\title{
MODERN LOGIC AND JUDICIAL DECISION MAKING: A SKETCH OF ONE VIEW
}

\author{
Layman E. Allen* and Mary Ellen Caldwell $†$
}

\section{InTRODUCTION}

Two hundred years elapsed before the nineteenth century logicians Boole, ${ }^{1} \mathrm{De}$ Morgan, ${ }^{2}$ and others, finally succeeded in formally developing the "calculus of reasoning" first suggested by the German mathematician, Leibniz. ${ }^{3}$ It is, perhaps, to the credit of the legal profession that less than one century has subsequently elapsed, and already some lawyers and legal writers, along with other scholars, are beginning to explore the relationship between modern logic and law. ${ }^{4}$

What is attempted here is to outline the bare bones of one tentative way of looking at the relationship between modern logic and the judicial decision process. From the useful vantage point of a Lasswellian social process framework of analysis, ${ }^{5}$ logic and judicial decision making are considered contextually within that total manifold of events that we call "the world." Thus viewed, the judicial decision making process is just one constituent of the complex unfolding of events through time. We

-A.B. 1951, Princeton University; M.P.A. I952, Harvard University; LL.B. I956, Yale University. Assistant Professor of Law, Yale University. Member of the Connecticut bar. Fellow, Center for Advanced Study in the Behavioral Sciences, 196r-62. Contributor to legal periodicals.

† B.A. 1943, N.S.C.L., Louisiana: LL.B. I955, Louisiana State University; LL.M. 1959, Yale University. Research Associate and Lecturer, Yale Law School. Member of the Louisiana bar. Associate Editor, Modern Uses of Logic in Law [M.U.L.L.].

1 1815-1864. George Boole, The Mathematical Analysis of Logic (1847); An Investigation of THE LAWS OF THOUGHT ( 1854 ).

${ }^{3}$ i 806-i 876. Augustus De Morgan, Formal logic: Or, The Calculus of Inference Necessary and Probable (i847); Syllabus of A Proposed Systed of Logic (1860).

${ }^{3}$ See Gottfried Wilhelar Leibniz, Dissertatio de ARte Combinatoria (1656).

+ Cohen, The Place of Logic in the Law, 29 HaRv. L. Rev. 622 (1916); Keyser, On the Study of Legal Science, 38 YALE L.J. 413 (1929); Berkeley, Boolean Algebra (The Technique for Manipulating 'And,' 'Or,' 'Not,' and Conditions) and Applications to Instirance, 26 RECORD OF AM. INST. OF Actuaries 373 (1937), 27 id. 167 (1938); Oppenheim, Outlines of a Logical Analysis of Law, I I PHIL. of Scr. r42 (1944); M. R. Cohen \& F. S. Cohen, Readings in JuRisprudence and Legal Phlosophy (1951); Wedburg, Some Problems in the Logical Analysis of Legal Science, 17 THeORIs 246 (I95I); Utrich KLUG, JURIstische LoGIK (I95I), (2d ed. 1958); Loevinger, An Introduction to Legal Logic, 27 IND. L.J. 47r (I952); Stoljar, The Logical Status of a Legal Principle, 20 U. CHI. L. Rev. 18I (I953); E. G. Maynez, Logica Dez JuRicio JuRidico (I955); Tammelo, Sketch for a Symbolic Juristic Logic, 8 J. Legal Ed. 277 (1956); Anderson \& Moore, The Formal Analysis of Normative Concepts, 22 AM. Socio. Rev. 9 (1957); Allen \& Orechkoff, Toward a More Systematic Drafting and Interpreting of the Internal Revenue Code: Expenses, Losses and Bad Debts, 25 U. CHI. L. Rev. I (x957); Allen, Symbolic Logic: A Razor-Edge Tool for Drafting and Interpreting Legal Documents, 66 YALE L.J. 833 (I957); O. C. JENSEN, The Nature of Legri Argument (I957); Anderson, The Logic of Norms, 2 Logique et Analyse 84 (1958); Fenix S. Cohen, The Legal Conscience: Selected Papers of F. S. Cohen (Lucy Kramer Cohen, ed. 1960); Simitis, The Problem of Legal Logic, 3 Ratro 60 (1960); Castañeda, Imperative Reasoning, 21 Phil. \& Phenomenological Research $2 \mathrm{I}$ (1960-6I); Ward Waddelt, JR., Structure of Laws As Represented by Symbolic Methods (1961); and Anderson, Logic, Norms, and Roles, 4 Ratio $36(1962)$.

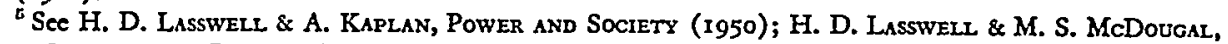
Law, Science and Policy: A Policy-Oruented Junusprudence (mimeo. 1957); H. D. Lassweil, The Decision Process (1956). 
attempt to represent some of the complexities involved in each of these processes and the relationships between them by means of a series of diagrams. By suggesting that we begin with the world as our context, we make no claim to describing it in complete detail. To the contrary, the sketch presented here-we would emphasize the word "sketch" and the word "tentative"-is rough, incomplete, and subject to considerable improvement. But one of our purposes will be served if the outline points the way toward cumulative efforts to achieve a comprehensive description of the judicial decision process. In addition to this broad look at logic, judicial decision making, and the world, a more modest aim is to describe, in some detail and with reasonable clarity, one aspect of the relation between logic and judicial decision making.

\section{I}

The Judictal Decision Process Within the Total Manifold of Events

In narrowing down to a focus on logic in the Judicial Decision Process, we first consider the position of the Judicial Decision Process within the total Manifold of Events. If we were to draw a picture of this, the result might look like Figure r.

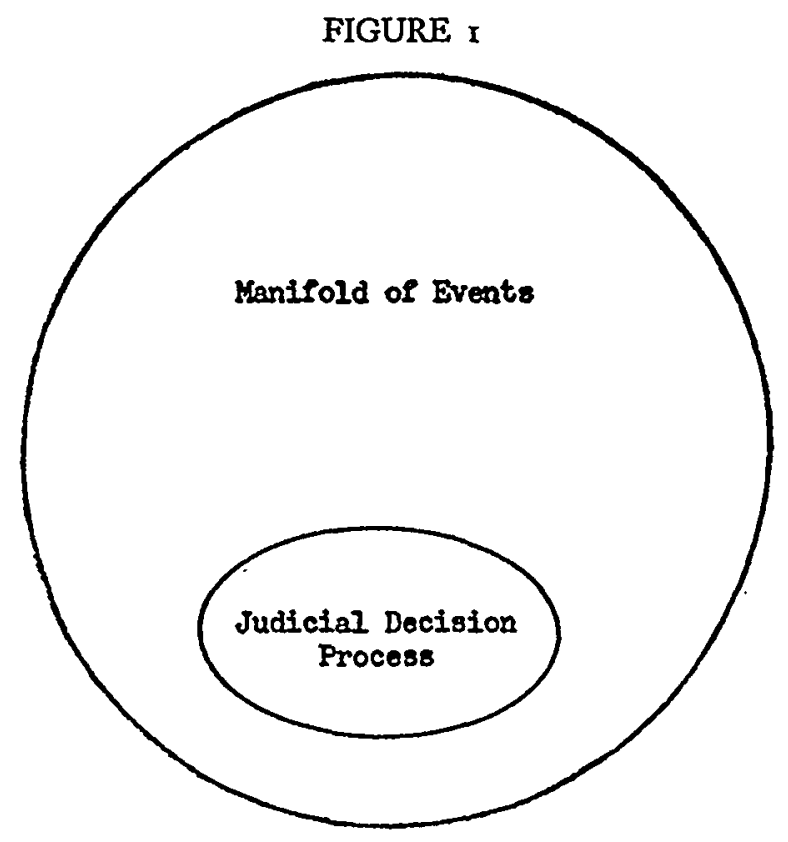

However, as we probe more deeply and wish to represent in somewhat greater detail the relationships between the total Manifold of Events and the Judicial Decision Process, we can lessen verbal and visual chaos by adopting the simple convention illustrated by Figure 2: 
FIGURE 2

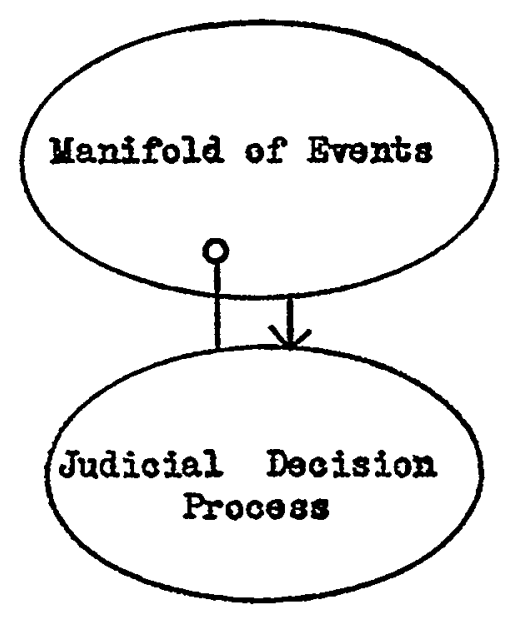

The" 1 "connection indicates that the Judicial Decision Process is a part of the Manifold of Events, while the " $\longrightarrow$ "connection indicates that some or all of the other parts of the Manifold of Events are inputs to the Judicial Decision Process. As will be seen later, this type of diagram is more useful for communicating intricate patterns of relationships.

From the point of view adopted here, the Manifold of Events is regarded as comprised of a great many outputs from past processes which serve as inputs to present processes that will, in turn, generate outputs to serve as inputs to future processes. (See Figure 3.) ${ }^{6}$

The following graphic representations of the Judicial Decision Process and its relation to the total Manifold of Events are in the form of a series of flow diagrams, each subsequent diagram in somewhat greater detail than the preceding one. ${ }^{7}$ Two of the most significant inputs to the Judicial Decision Process highlighted here are the Decision Makers (in the case of courts, the judges) and the Claims to be Litigated. Both of these are (I) parts of the total Manifold of Events that feed into the Judicial Decision Process (as shown in Figure 4) and (2) important determinants of the Decision that is a resulting output from that process.

By the term Decision Makers we intend to refer to those persons (with all the perspectives that they have acquired during their life experience) who have been designated as the official arbiters of disputes in the name of the community. In Figure 5 it is indicated that some Human Beings who acquire perspectives (demands, identifications, expectations) by virtue of their Participation in the Social Process

\footnotetext{
- Whether a given event is to be regarded as an input, as a process, or as an output, will depend upon the purposes for which the analysis is being made.

7 The analysis presented here is a revised and more comprehensive version of an earlier attempt at such 2 description. See Allen, Modern Logic: A Useful Language for Lawyers, in EdasR A. Jones, JR. (ED.), Law and Electrontcs: The Challenge of a New ERa 448 (1962).
} 
FIGURE 3

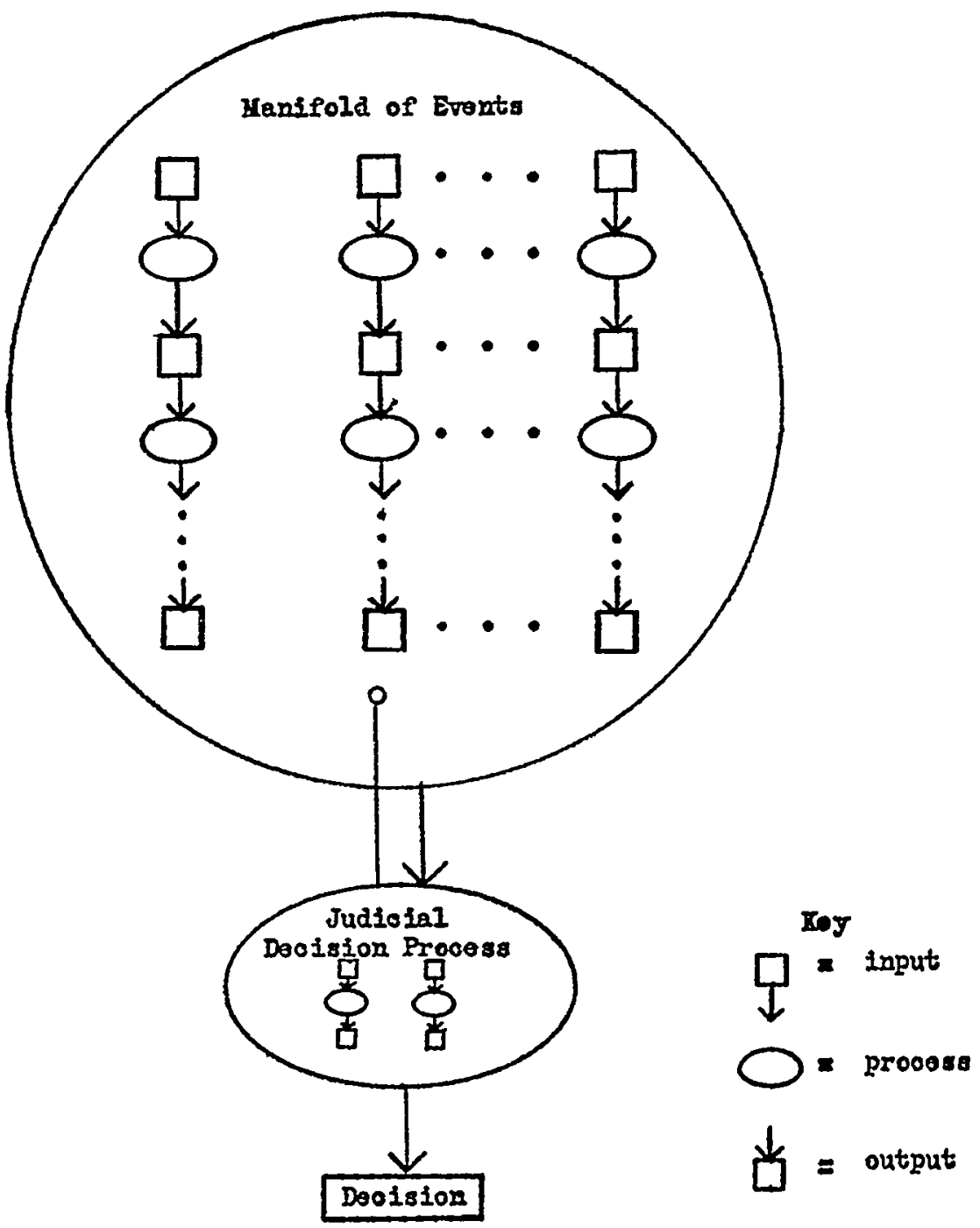

become Decision Makers. ${ }^{8}$ There are Other Persons with Perspectives that are outputs from Participation in the Social Process. Some of these Other output events may or may not-along with all of the other events in the Manifold of Events -be among the Precipitating Events that by means of a Selection Process may become one of the Claims to be Litigated.

'A pereeptive comment on the relevance of Decision Makers' perspectives is Fred Rodell's recent statement: "Only by examining the Justices individually as whole human beings, by probing beneath the protective shell of principles expressed in opinions, to try to find what made or makes cach Justice really tick, can past decisions be explained without constant contradiction and future decisions predicted with a surprising degree of accuracy." Rodell, For Every Iustice, Iudicial Deference is a Sometime Thing, 50 GEo. L.J. 700, 701 (1962). 


\section{FIGURE 4}

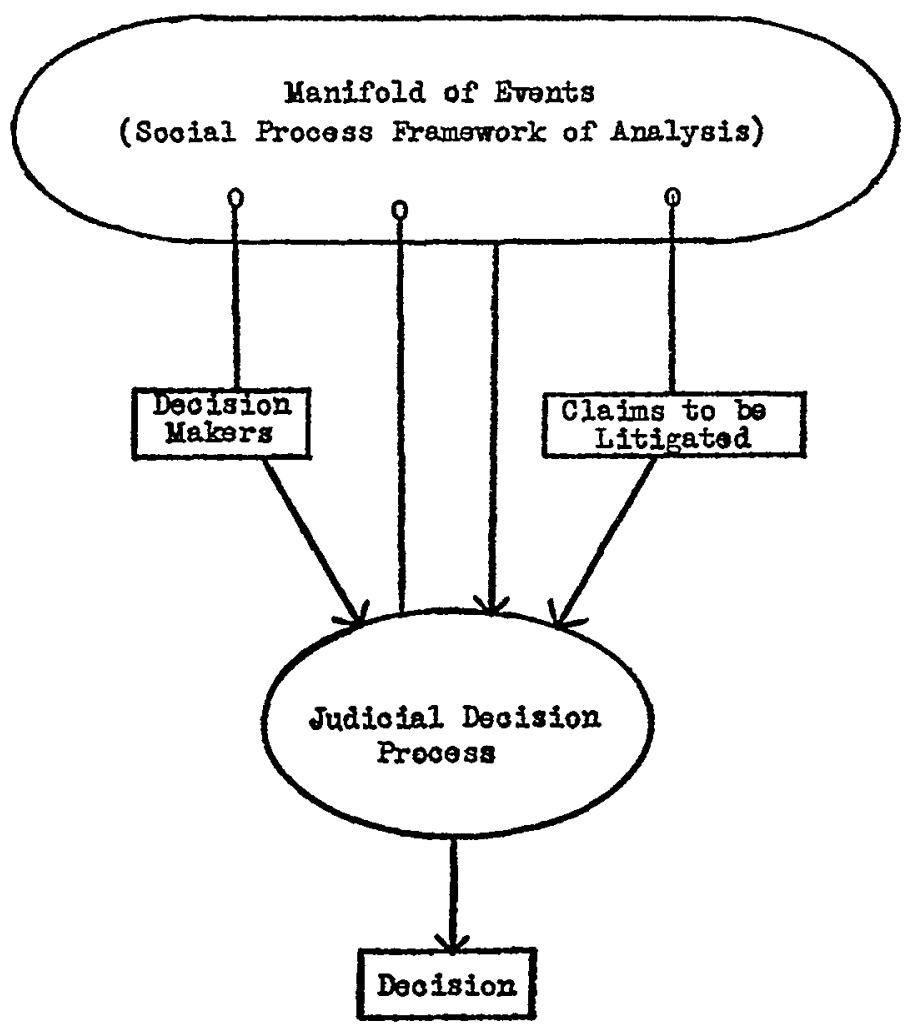

As indicated by the center " $\rightarrow$ " feeding into the Judicial Decision Process (Figure 5), some or all of the rest of the events in the Manifold of Events (those other than the Judicial Decision Process) are inputs to the Judicial Decision Process and determinants of the Decision which is its output. Thus, the events that are inputs to the Judicial Decision Process are classified into three categories: Decision Makers, Claims to be Litigated, and a residual category which contains all the other events in the rest of the Manifold of Events that are not Decision Makers and not Claims to be Litigated.

This way of approaching a description of the Judicial Decision Process suggests that it is related to "everything else in the world." Such a comprehensive approach permits and encourages incorporation of the findings of all investigators to contribute to an understanding of the Judicial Decision Process (that is, to our knowledge of the relation of it and its parts to other events in the world and the relation of its parts to each other). Our focus of attention in this article is the relation between formal logic and the Judicial Decision Process; and of that, we attempt only a partial sketch. 
FIGURE 5

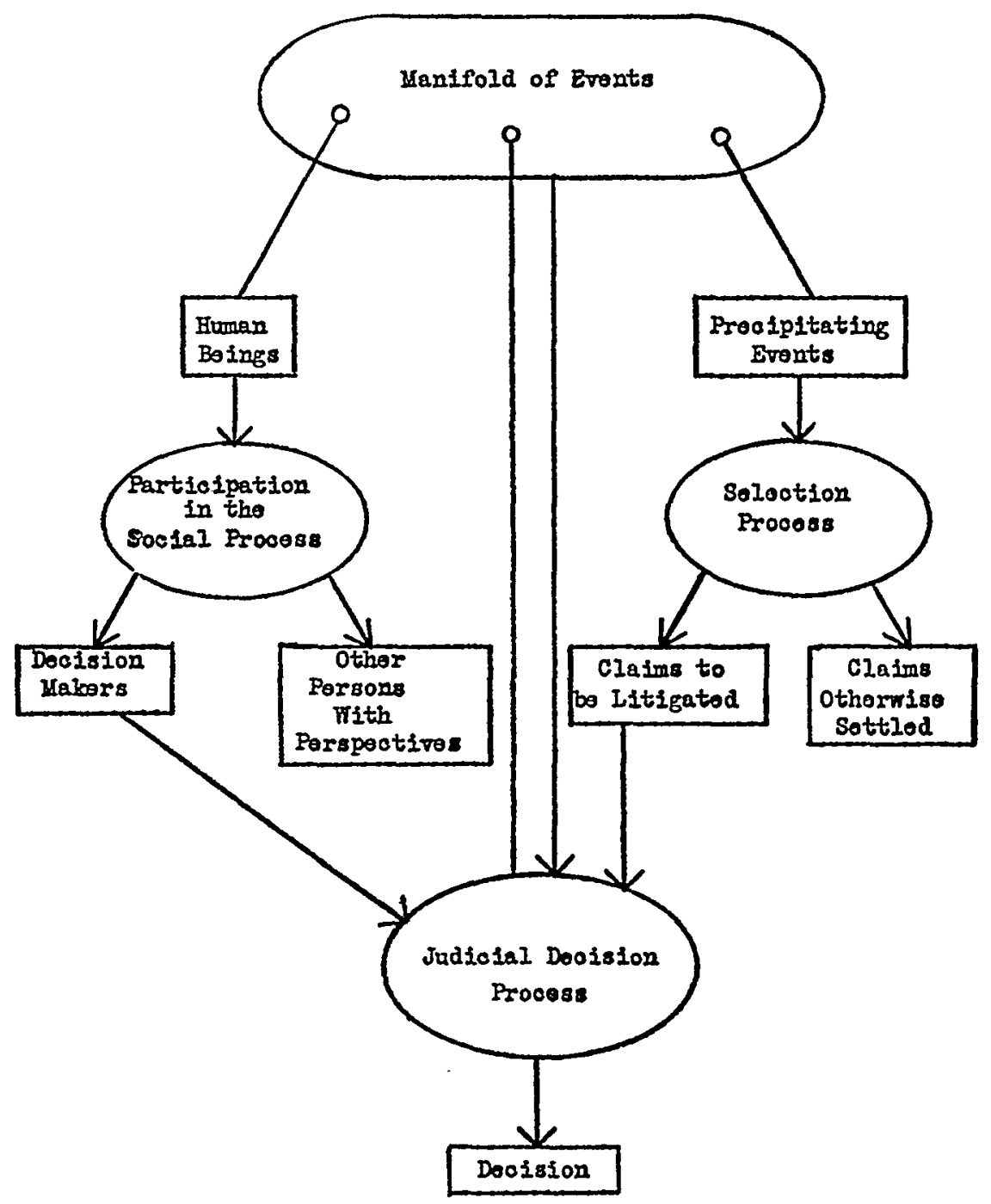

A. Inputs-Process-Outputs

The input-process-output vocabulary and the diagrams we have been using are not a bag of tricks to be applied mechanically. They assume a precise and somewhat technical usage of the term "process." It is useful to digress a bit at this point in order to give some illustration of processes transforming inputs into outputs. One way of achieving some understanding of a process is to examine what it does. By analyzing certain of its inputs and outputs we may be able to specify what that process will give as outputs for certain other inputs; and thus, if successful, we will be able to accurately predict some events related to that process and, to that 
extent "understand" that process. The application of a process to an input. resulting in an output can be represented by:

Process (input) $=$ output

If we examine a given Process A and observe that from the word "fun" as an input, this process produces the word "bun" as an output, then we have some clue about the nature of that process. If we examine another input to that process, say "fell" and find that it results in the output "bell," we are inclined to think that the process is one that converts expressions that begin with an " $f$ " into like expressions that begin with a "b." More concisely we might say:

Process A (f...) $=(b \ldots)$

that is, Process $A$ applied to input $f$... equals output $b$.... If our hunch about the process is correct, then from inputs:

fall freeze flip ferry fore fox fin

to Process $A$, we would expect to get as outputs:

ball breeze blip berry bore box bin

Thus Process $A$ would be one that transforms inputs into outputs that are related to the inputs in two ways:

(r) where the input has an initial letter "f" the output has an initial letter "b," and

(2) the rest of the letters in the output are exactly the same as the rest of the letters in the input.

Consider a second process-namely, Process B that takes inputs:

small fast big tasty

and transforms them into outputs:

smaller faster bigger tastier

At first glance, it may seem that Process $B$ relates its inputs and outputs in a way similar to the way that Process A relates its inputs and outputs; but closer scrutiny indicates that the outputs of Process B are not merely the inputs plus the suffix "er." From this further examination of the relationship between the inputs to and the outputs from Process B above, we would probably predict that inputs:

shiny slim fat

to Process B would result in outputs:

shinier slimmer fatter

and we would be right. Thus, Process $B$ would be a quite different kind of process from Process $A$; Process $A$ depends on the letters alone contained in its input words in determining what its output words will be, while Process B depends on the meaning expressed by its input words in determining what its output words will be. One 
way of characterizing the transformation which Process $B$ makes upon a given input is the following:

Process B (word expressing a property) = (word expressing more of that property)

But the inputs and outputs of processes need not be confined to words. Given that inputs to Process C:

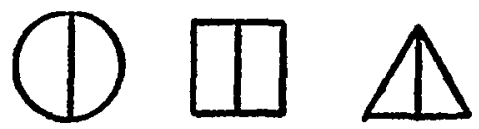

result in outputs:

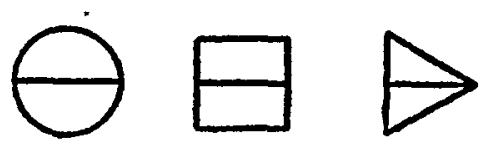

we would probably achieve a high degree of consensus about what output from Process $\mathrm{C}$ to expect from input:

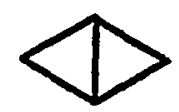

More interesting processes (more interesting in terms of their similarity to the representation of the judicial decision process that will be presented here) are some that have numerals as inputs and outputs. With numeral input-outputs we can illustrate processes that are simple and obvious; but also some that are quite subtle and complex, or at least appear to be so until they are understood.

If the inputs to Process D:

$$
\begin{array}{lllll}
0 & \text { I } & 3 & 4
\end{array}
$$

result in the outputs:

$$
\begin{array}{lllll}
0 & 2 & 4 & 6 & 8
\end{array}
$$

then we would probably feel rather confident that input "8" to Process D would result in output "I6." One way of characterizing the relationship between Process $D$ and its inputs and outputs would be:

Process D (Input $I_{n}$ ) $=$ (Output $O_{n}$ )

More specifically (and more briefly):

$2 \times\left(\mathrm{I}_{n}\right)=\left(\mathrm{O}_{n}\right)$ where " $\mathrm{x}$ " indicates multiplication.

Another rather obvious process would be Process $\mathrm{E}$, in which inputs:

$$
\begin{array}{lllll}
0 & \text { I } & 2 & 3 & 4
\end{array}
$$

result in outputs:

$$
\text { .. } \times 3579
$$

The relationship between Process $\mathrm{E}$ and its inputs-outputs is expressed by:

$\therefore\left[2 \times\left(I_{n}\right)\right]+I=\left(O_{n}\right)$ 
However, some processes may be considerably more subtle. Consider Process F, which when fed the inputs:

$$
\begin{array}{lllll}
0 & 2 & 3 & 4
\end{array}
$$

produces the outputs:

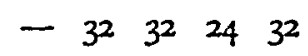

Readers may wish to test their understanding of Process $F$ by attempting to predict what the output from Process F will be when the input is " 5 ." (The answer is " 40. ") Given the further information about Process $\mathrm{F}$ that inputs:

$$
\begin{array}{lllllllllll}
0 & I & 2 & 3 & 4 & 5 & 6 & 7 & 8 & 9 & \text { Io }
\end{array}
$$

result in outputs:

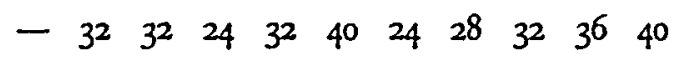

how many readers would be sufficiently confident of their understanding of Process $F$ to care to predict the output corresponding to input "II"? (The answer is "22.") even when informed that the further inputs:

$$
\begin{array}{llllllllllll}
\text { II } & 12 & 13 & \text { I4 } & 15 & 16 & \text { I7 } & \text { I8 } & \text { I9 } & 20 & 21 \ldots
\end{array}
$$

result in the outputs:

$$
\begin{array}{lllllllllll}
22 & 24 & 26 & 28 & 3^{30} & 3^{2} & 34 & 3^{6} & 3^{8} & 4^{0} & 42 \ldots
\end{array}
$$

which readers-even if able to predict accurately that input " 22 " results in output " 44 " that input "23" results in ouput " 46 ," and so on-would care to attempt an accurate and comprehensive description of the process that transforms this set of inputs into this set of outputs? Members of professions that are too firmly wedded to English prose as the exclusive means of communicating ideas might find such a description to be a somewhat formidable task. Fortunately, other communication tools are available-even if lawyers are not yet much accustomed to using them. One alternative is a flow diagram which indicates the subsidiary inputs-outputs and processes of a more general process. In describing Process $\mathrm{F}$ by means of a flow diagram, it becomes evident that Process $\mathrm{F}$ is not nearly as complex as it may have seemed at first. The information that we have about the outputs that result from given inputs to Process $F$ enable us to state with some confidence that the following flow-diagram description of Process $\mathrm{F}$ accurately accounts for all of the information that we have.

The description of Process $F$ that is provided by Figure 6 has one feature that should be especially noticed: that is the feedback loop from the "(B) $>2 \mathrm{I}$ ?" (that is, from the question: "Is the contents of address B greater than 2I?") to the address A. Such feedback loops are particularly useful when we attempt to describe the Judicial Decision Process in more detail.

- Figure 6 indicates that Process $\mathrm{F}$ can be analyzed into a pair of subsidiary input-

\footnotetext{
"This dòes not mean, however, that we may not wish" to alter our description of Process $F$ on the
} basis. of further empirical evidence, i.e.; more input-output combinations. 
'FIGURE 6

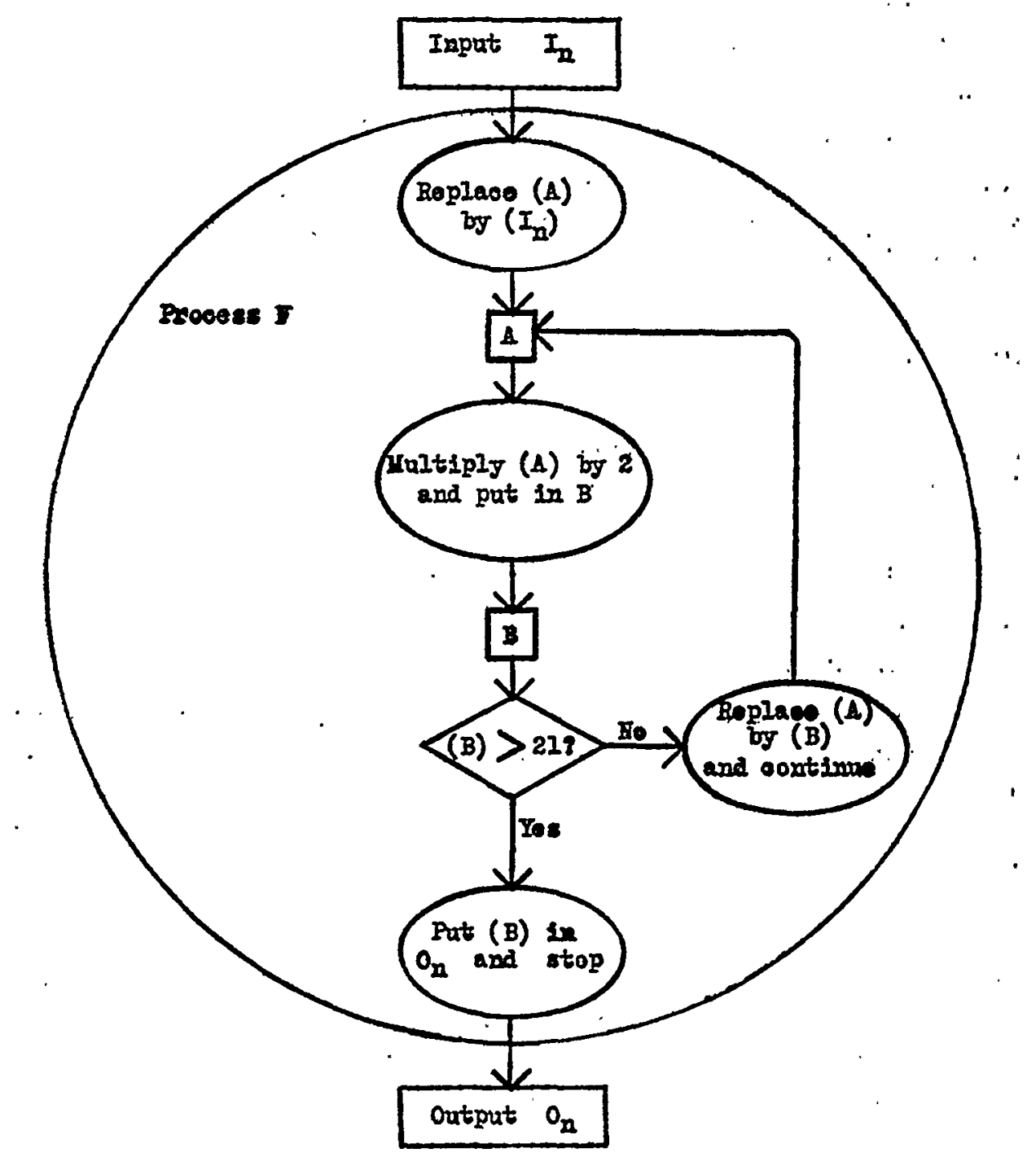

outputs and three subsidiary processes, the third subprocess itself being comprised of a branching question and a pair of subprocesses. Suppose that input $I_{n}$ is " 3 "; let us see how the subsidiary parts of Process $F$ operate to generate output $O_{n}$ of " 24 ." The first subprocess of Process $F$ puts the contents of $I_{n}$-symbolized by " $\left(I_{n}\right)$ "-into address $A$, replacing whatever contents may have been there before. The second subprocess then takes (A) (that is, the contents of address $A$, now; since the input $I_{n}$ was " 3 ," (A) is now " 3 ") and multiplies it by 2, putting the result in address $B$ to replace whatever contents may have been at $B$ before. Next, the contents of address $B$ is examined and the question is asked: "Is the contents of B a numeral 
larger than '2 $I$ '?" If the answer to this question is "Yes" then (B) is put in $O_{n}$ to become the output $O_{n}$ and Process $F$ stops. However, since (A) was " 3 ," (B) will be " 6 ," and the answer will be "No." If the answer is "No," then (A) is replaced by (B) (that is, " 3 " in A is replaced by " 6 "). Thus, on this second pass through $A$, its contents will be "6"; and the process will continue. On the second pass through $B$, its contents will be (A) $\times 2$ (that is, $I 2$ ); and the answer to the question, "(B) $>$ 2I? will still be "No." On the third pass (A) will be "r2," (B) will be "24," and the answer will be "Yes." Therefore, (B)-namely, " 24 "-will be put in $\mathrm{O}_{\mathfrak{n}}$ to become the output and the process will stop. This obtaining of output " 24 " from input " 3 " by looping back through the feedback loop in Process $F$ three times can be summarized by the following tabulation:

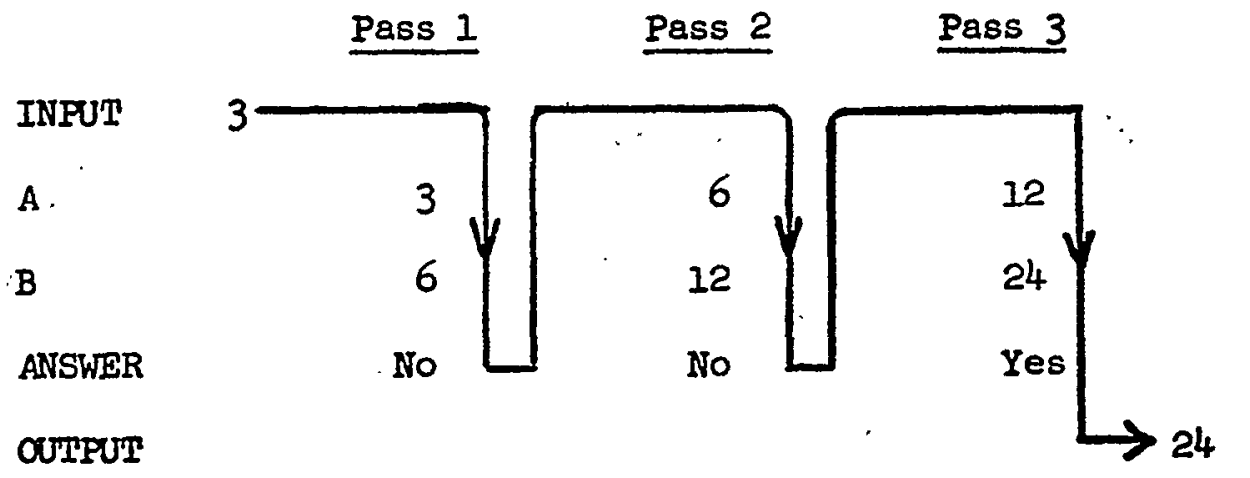

If the input to Process F were "2," then the following table would summarize the four passes through the feedback loop of Process $F$ that would result in the output " 32 ":

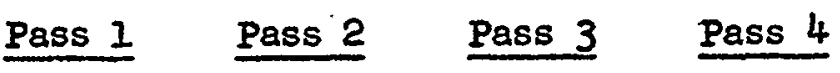

\section{INFUT}

A

B

ANSWER
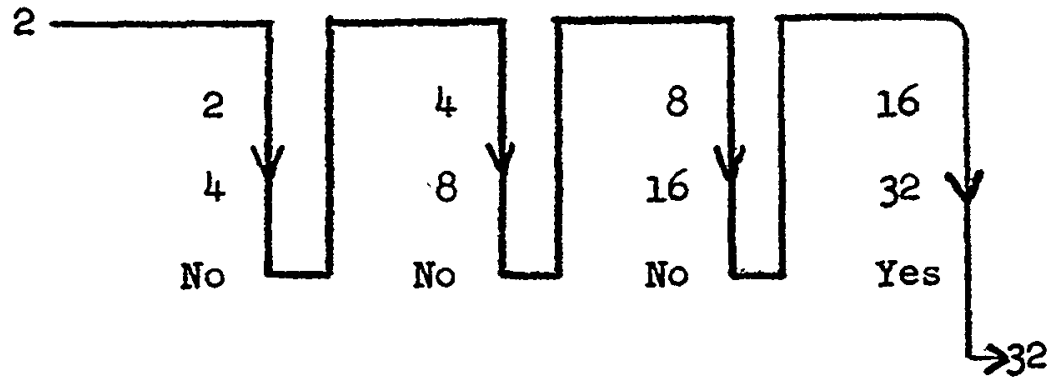

QTPEOT

The above illustrates how Process $F$ can be described by means of a flow diagram. In preceding examples, Processes $\mathrm{D}$ and $\mathrm{E}$ were also described by equations. Process $F$ can, similarly, be described by the following equation:

$$
2^{a} \times\left(I_{n}\right)=\left(O_{n}\right)
$$

where: $(\mathrm{I}) \mathrm{a}=$ the minimum $\mathrm{b}$ such that $\left[2^{\mathrm{b}} \mathrm{x}\left(\mathrm{I}_{\mathrm{n}}\right)\right]>2 \mathrm{r}$, and

(2) $b \in\{0,1,2,3, \ldots\}$ 


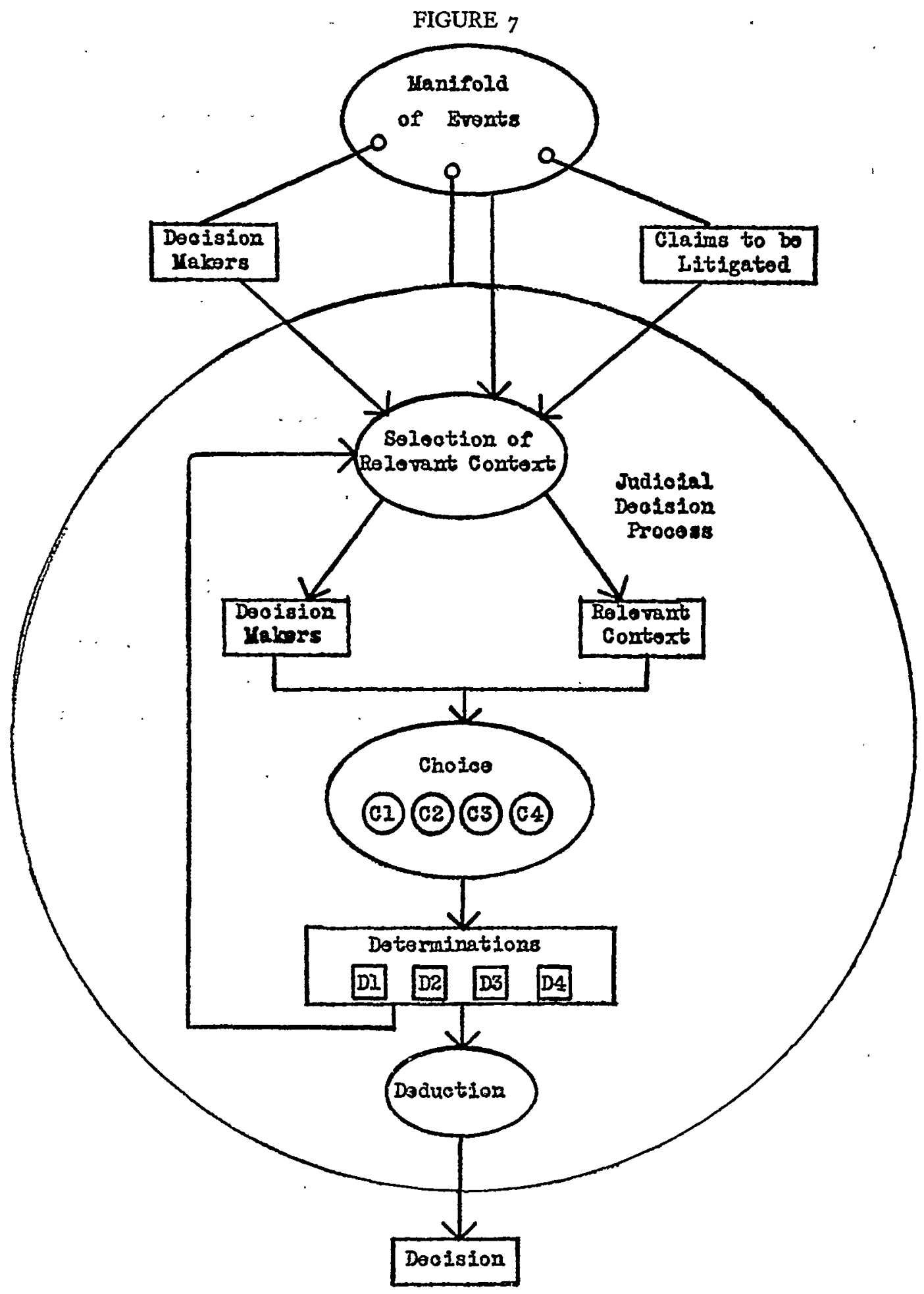


For lawyer-readers who are more accustomed to communicating in English prose than in mathematical notation, it is likely that the flow diagram of Process $F$ more effectively communicates a description of that process than the equation. On the hunch that the same may be true of the Judicial Decision Process, the description of it that follows will be presented in the form of flow diagrams, rather than in mathematical notation.

\section{B. Flow Diagrams of the Judicial Decision Process}

As we grope toward some understanding of relations among the parts of the Judicial Decision Process, it seems useful and appropriate to create categories of analysis that will enable us (I) to reduce the number of events to be dealt with to manageable proportions, yet remain comprehensive, (2) to focus on the logical aspects of judicial decision making, and (3) to deal adequately with the other important aspects of the Judicial Decision Process. An analysis of the Judicial Decision Process into the three subprocesses of Selection of Relevant Context, Choice, and Deduction with appropriate inputs and outputs provides one convenient set of categories for describing the relations between formal logic and other aspects of the Judicial Decision Process. A flow diagram of the Judicial Decision Process thus analyzed is indicated in Figure 7.

With such a comprehensive set of inputs as all of the rest of the events of the world, the Judicial Decision Process as conceived of here has as its first subprocess one in which the Decision Makers and Claims to be Litigated interact as inputs in selecting from all the other inputs from the Manifold of Events that subset of events which is to be regarded as the Relevant Context. For each different controversy that comes before a court, there will be a different Relevant Context. In addition to being diagrammed as an input to the Selection of Relevant Context process, Decision Makers are also shown as an output from that process. . This is done to emphasize the fact that by the judges' participation in the process of deciding a given case, their perspectives may in fact be so altered that they are significantly "different" Decision Makers from those they were before they began consideration of that case. Both the Decision Makers and the Relevant Context are inputs to the Choice process. At this level of analysis, both this Choice process and its output (Determinations) are extremely vague. In a subsequent diagram these will be analyzed in greater detail.

The feedback loop from Determinations to the Selection of Relevant Context process indicates that what happens in the Choice process, in turn, affects what happens in the Selection of Relevant Context process, as well as vice-versa. Just as was illustrated in the flow diagram of Process $F$ that (depending on what the input was) there might be a number of "passes" through the feedback loop, Figure 7 indicates that there may be a number of passes through the feedback loop from Determinations to Selection of Relevant Context. In Process $F$, the contents of address $A$ and address $B$ at various times in the analysis were success approximations of the contents that ultimately determined what the output would be. Similarly, 
the contents of Decision Makers, Relevant Context, and Determinations are, at various times in the analysis, successive approximations of the contents that will ultimately feed into the Deduction process and determine the Decision. The criteria for determining when Process F would cease cycling around its feedback loop were explicit and precise; but the criteria for determining when the Judicial Decision Process will cease cycling around its feedback loop are far from clear. However, even though the criteria are unclear, for each controversy a point is reached sometime when the Determinations branch into the Deduction process, rather than cycling back into Selection of Relevant Context and through the Choice process once again. At that point, the final Determination somehow gets "crystallized" and a Decision results from their feeding into Deduction as inputs.

How a decision is precipitated by means of Deduction from the outputs of the Choice process will, perhaps, be clarified by the consideration of the subprocesses of the Choice process and the Determinations that are their outputs. The subprocesses are:

(I) Fact Determination

(2) Rule Selection

(3) Semantic Rule Interpretation

(4) Syntactic Rule Interpretation

Their outputs are:

(I) Conclusions about Facts Determined

(2) Conclusions about Rules Selected

(3) Conclusions about Semantic Interpretation of Rules

(4) Conclusions about Syntactic Interpretation of Rules

The relations between these (I) subprocesses and outputs and (2) the rest of the Judicial Decision Process are summarized in Figure 8.

The Conclusions about Facts Determined are statements (explicit or implicit) of a Decision Maker's ideas about what events he, for purposes of deciding the dispute in question, is going to regard as having occurred, and the Fact Determination process is the operation that the Decision Maker engages in for the purpose of reaching such conclusions. How accurately these Conclusions about Facts Determined describe the events that have actually transpired will depend upon the effectiveness with which information has been retrieved and communicated prior to and during the course of litigation, as well as the perceptiveness and predispositions of the Decision Maker. As he receives more and more information about a case, a Decision Maker may change his mind several times about what events actually occurred and his own Conclusions about Facts Determined for purposes of deciding the case. How many times will he form some judgment, only to discover that his provisional conclusion is untenable in relation to another part of the context? How many cycles through the feedback loop he will make in a particular case is impossible to 


\section{FIGURE 8}

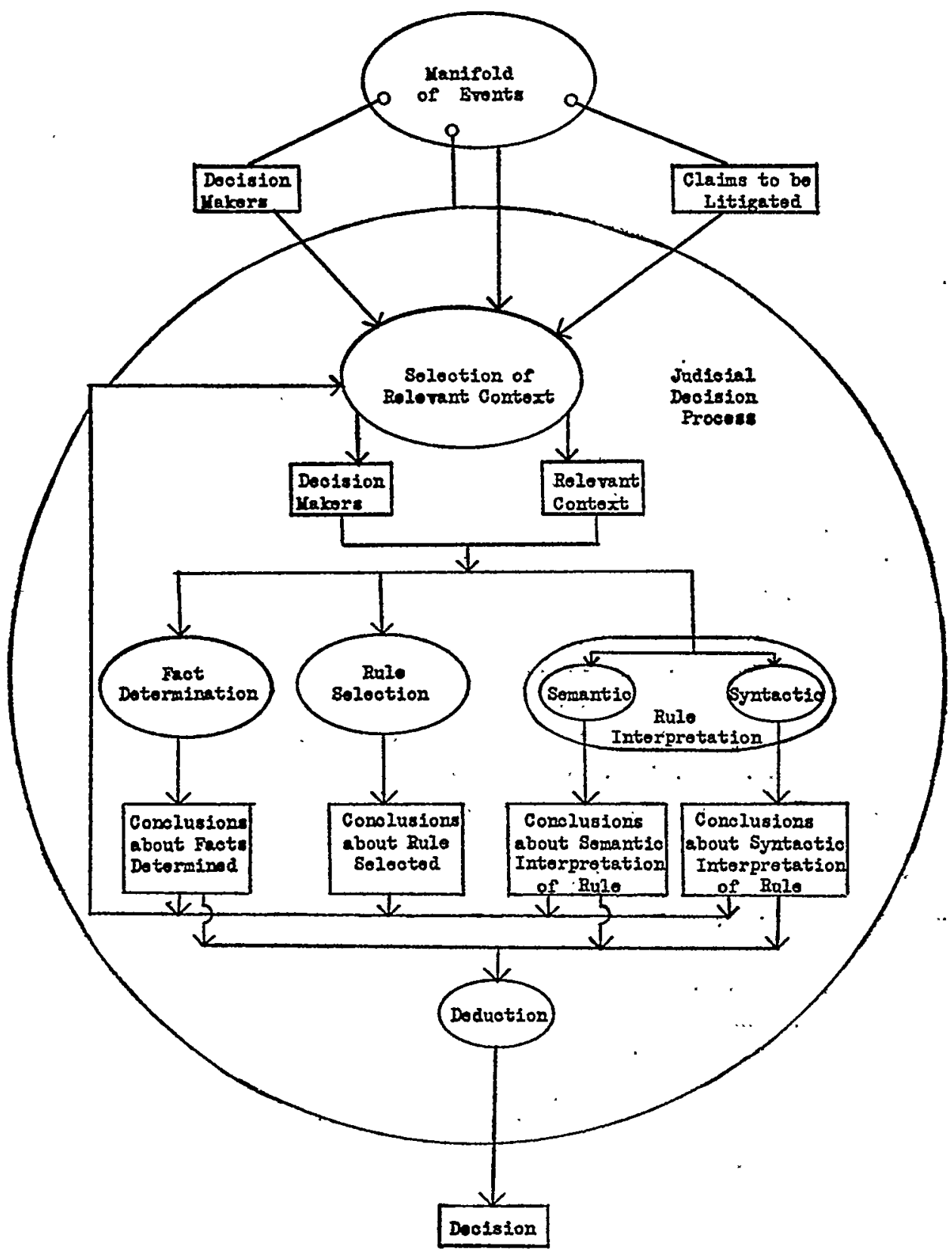

say. But whatever cycling occurs, clearly occurs concurrently with operations going on in the other subprocesses of the Choice process.

The Conclusions about Rules Selected are statements of the Decision Maker's ideas about what legal norms he is going to regard as applicable to the facts de- 
termined to have occurred. The Rule Selection process is the operation that the Decision Maker engages in for purposes of reaching such conclusions. A Decision Maker may cycle through the feedback loop to Selection of Relevant Context a number of times before settling finally on just which norms to apply. Certainly, if he changes his mind about the facts determined to have occurred, he may also reconsider, and possibly change his mind about the appropriate norms to apply to those facts.

The other two of the subprocesses of the Choice process are concerned with interpreting the rules selected. The rules themselves are in (or can be transformed without changing their meaning into) the form of an "if-then" statement which asserts: ${ }^{10}$

If certain conditions are fulfilled,

then certain legal consequences follow.

The Semantic Rule Interpretation process is concerned with relating ( $I$ ) the facts determined to (2) the antecedent of the rule selected-that is, with deciding whether or not the events determined to have occurred fulfill the requisite conditions specified by the antecedent of the selected rule. In this process attention is focused intensively upon the individual words and phrases used in the antecedent of the rule and what it is appropriate to read them to mean. What the whole antecedent of the selected rule is interpreted to mean will influence the decision about whether the events determined to have occurred fulfilled the conditions specified in the antecedent, and the meaning given to the whole antecedent depends to a considerable extent upon the meaning given to its individual words and phrases.11

Syntactic Rule Interpretation, on the other hand, is not concerned with the role of the meaning of individual words and phrases in determining the meaning of the antecedent of a rule; rather, it is concerned with the meaning of the overall rule and how its meaning is influenced by the relations intended between the individual words, phrases, and sentences within that rule. The syntax of the antecedent will determine which combinations of conditions need to be fulfilled in order to reach the consequent, and the syntax of the consequent will determine which combinations of legal consequences follow, that is, what is forbidden, permitted, or

\footnotetext{
${ }^{10}$ Allen, Toward a Procedure for Detecting and Controlling Syntactic Ambiguity in Legal Discourse, in 3 Allen Kent (ED.), Advances in Documentation Part 2 (1960).

${ }^{11}$ For example, if it has been determined as a fact $(r)$ that a definition and standard of identity has been prescribed by regulations for "fruit jam," (2) that a seller is seeking to market a food product labeled "Delicious Brand Imitation Jam," and (3) that the food product does not meet the minimum requirements of the prescribed definition of "fruit jam"; and an applicable rule states: "If ( $I$ ) a product purports to be or is represented as a food for which a definition and standard of identity had been prescribed by regulations, and (2) the product does not conform to that standard, then (3) that product shall be deemed to be misbranded," have the conditions specified by the antecedent of the rule been fulfilled? More specifically, does a product labeled "Delicious Brand Imitation Jam" purport to be, or is it represented as, "fruit jam"? In determining whether the determined facts fulfill the specified condition, the meaning attributed to the words "purports" and "represented" is of critical importance. Attributing meaning to such words and determining whether such a condition is fulfilled is an example of Semantic Rule Interpretation.
} 
required. Thus the determination of what syntactical interpretation of the rule is appropriate is a matter of no minor significance; it may affect whether or not the requisite conditions specified by the antecedent are fulfilled, and it may affect what consequences follow if the conditions are fulfilled. If a rule is well drafted, interpreting it syntactically is relatively simple and clear cut.

In fact, if some standardization of the words used to denote syntactical connections is adopted, this kind of interpretation is sufficiently routine that it can be done by means of a digital computer or some other automatic data processing device. However, most legal rules are not sufficiently well drafted to make feasible this kind of treatment. Many of the rules in law, as well as other statements in legal literature, are syntactically ambiguous and reasonably admit of more than one interpretation because of this ambiguity. The major theme of this article is that some of the techniques used in modern logic are useful in ferreting out various possible interpretations from such syntactically ambiguous legal language. Furthermore, as a step in the right direction toward minimizing litigation-preventive law, if you wishthese same techniques can be used to help improve legal drafting at the outset by eliminating such ambiguities as may be inadvertently incorporated. Before considering in some detail how such techniques can be used to improve the drafting and interpretation of legal rules and documents, we shall want to complete our brief examination of the total context of which this Syntactic Rule Interpretation process is a part. In particular, we shall briefly consider the Deduction involved in the Judicial Decision Process, and then trace a particular case through the Judicial Decision Process as described here.

It should be evident from the description of the Judicial Decision Process here presented that we regard the predispositions of the Decision Makers as formed by their individual life experiences as the crucial element in determining how competing Claims to be Litigated are resolved.

One important aspect of a Decision Maker's official activities that gives some clue to what goals he is pursuing in his official behavior are the opinions that he writes and the opinions of others that he subscribes to with a favorable vote. In these official writings, the statements that judges make about their Conclusions (about Facts Determined, Rules Selected, Semantic Interpretation of Rules, and Syntactic Interpretation of Rules) reveal to a considerable extent the attitudes and predispositions that are influencing the choices they make. The four subprocesses of the Choice process pose the crucial choices whose resolutions determine the outcome of a particular case. The Deduction that follows the Determinations made in the Choice process is quite simple by comparison. For example, the outputs of the Choice process that are inputs to Deduction might be in the following form:

(I) $\mathrm{F}$

(2) If $F$, then $A$. Where " $A$ " is the statement of the conclusion that the requisite conditions in the antecedent of the rule have been 
fulfilled, and "If $F$, then $A$ " is the Semantic Interpretation of the Rule

(3) If $\mathrm{A}$, then $\mathrm{C}$. where " $\mathrm{C}$ " is the statement of the legal consequences of the antecedent conditions being fulfilled, and "If $A$, then $C$ " is the Syntactic Interpretation of the Rule.

Then what results as an output from Deduction is:

(4) C

Deduction in such an example as this one is the simplest of all the processes we have attempted to describe. That the Deduction involved in most judicial opinions is similarly simple probably accounts for the fact that judges rarely, if ever, make explicit just what system of logic they are using to perform this Deduction. Whatever system of reasoning is being used to proceed from a set of premisses to a conclusion that follows from them is left implicit-unarticulated in what is said in the opinion. If the system of logic in effect being used were somehow, somewhere, made explicit, it could be more easily examined to determine whether or not it is the most suitable system for the particular purposes at hand. Once aware that there is more than one system of logic that one might wish to consider as the appropriate system to use in the Deduction process, lawyers.might also wish to add some explicit reçognition that there is a fifth subsidiary process in the Choice process-namely, a Selection of Logical System process with an output of a Logical System Selected, which is an input to the Deduction process.

\section{De Sylva v. Ballentine"}

In the second half of this paper we will focus on Syntactic Rule Interpretation, and the discussion will be limited to this subprocess of the process of Choice. In concluding this section, however, it will serve two purposes to look at one piece of litigation through both ends of the telescope-one view, to locate the Decision in the total Manifold of Events; the other, to clarify the interrelations among the several subprocesses of Choice.

The case to be considered in some detail is De Sylva v. Ballentine. ${ }^{12}$ For convenience, we might say that the Precipitating Events began in California on July II, 1950, when song writer George De Sylva died. He left a widow, Marie De Sylva; a will acknowledging an illegitimate minor, Stephen William Ballentine, as his son; and a number of copyrights on musical works. ${ }^{13}$ Thereafter, the widow applied for and received renewals on many of the copyrights registered in the name of her

\footnotetext{
${ }^{12} 351$ U.S. 570 (1956). Although we shall make occasional references to the proceedings in the district court and the court of appeals, we concentrate here upon the Judicial Decision Process in the United States Supreme Court.

${ }^{13}$ Such as "California, Here I Come" (with A. Jọlson and J. Meyer), and "Look for the Silver Lining" (with Jerome Kern).
} 
husband, ${ }^{14}$ whereupon Marie Ballentine, the mother of the child and guardian of his estate, sought to have her son share with the widow in the copyright renewal and the moneys and benefits obtained by the widow as a result of the copyright extensions. Both the widow and the mother made inquiries of the Copyright Office, ${ }^{15}$ and its Principal Legal Adviser replied that in practice ${ }^{16}$

... joint widow-children renewal claims are registered without correspondence. This differs from cases where a claim is asserted contradicting one which has already been registered, since we make a practice of requesting an explanation in such instances, before proceeding with entry of the inconsistent claim.

That the mother-guardian and the widow were unwilling to settle their differences by private negotiation is clear from their filing, respectively, a. Complaint for Declaratory Relief and a Motion to Dismiss. From the dry pages of a Transcript of Record, however, one hardly begins to sense what other of the total Manifold of Events fed into their decision to litigate.

The record is even more barren of relevant information about one of the most significant factors in any case-the predispositions of the.Decision Makers. However, their social, educational, and political backgrounds are continuously subjected to analysis in the legal, public, and scholarly press. Although their deep-seated convictions and the vagaries of their pre-judicial careers are. unarticulated in the record, these are crucial constituents of the Manifold of Events that ultimately determine the decision. In this case, Mr. Justice Harlan wrote the majority opinion $^{17}$ and Mr. Justice Douglas, joined by Justice Black, entered a separate concurring opinion.

Much of what is here labeled Selection of Relevant Context is a function of those rules of law and practice which demand a "frozen record from below"18 and forbid appellate review of "findings of fact." In this case, the district court had held that the minor was a child within the meaning of the term "children" as used in the Copyright Act, but that the renewal rights belonged exclusively to the widow so long as she is alive. The court of appeals agreed with the district court on the first point, but held that on the author's death both the widow and the child shared in the renewal copyrights. By the Stipulation of Facts in the trial court and by confining her petition for certiorari to the questions ( $I$ ) whether the "widow, widower, or children" take as a class, or in order of enumeration, and (2) whether

14 The present Copyright Act, 61 Stat. 652, 17 U.S.C. $\$ 24$ (1958), provides for a second 28 year copyright after the expiration of the original 28 year term. The pertinent part of $\$ 24$ reads as follows: "that . . the author of such work, if still living, or the widow or widower, or children of the author, if the author be not living, or if such author, widow, widower, or children be not living, then the author's executors, or in the absence of a will, his next of kin shall be entitled to a renewal and extension of the copyright...."

${ }^{18}$ The letters requesting advice from that office do not appear in the Transeript of Record.

10 Transeript of Record, p. Ix.

${ }^{17}$ Joined by Chief Justice Warren and Associate Justices Reed, Frankfurter, Burton, Clark, and Minton.

19 See Karl. N. Llewellyn, The Comaron Law Trabimon-Deciding Appears ig et seq. (I960). 
"children" includes an illegitimate child, the widow was instrumental in narrowing the factual component of Relevant Context.

The record reveals, however, that Relevant Context was simultaneously inflated by amicus curiae briefs of four private associations ${ }^{19}$ and a memorandum for the Register of Copyrights. These latter documents opened up policy questions of less immediate and crucial interest to the contending parties, but of great concern to the amici. The associations concentrated on the economic aspects of case, arguing that a decision in favor of the minor would injure the marketability of literary works and cast a cloud on the exclusivity of rights heretofore purchased by them. The Register of Copyrights addressed himself to the history of copyright legislation and the practice of the Copyright Office. Out of these and other unknown elements of the Relevant Context, the Decision Makers began somewhere to choose.

If Fact Determination were limited to what is conventionally labeled "findings of fact," then, theoretically, Choice at the appellate level would not include this subprocess. Instead, Conclusions about Facts Determined that are made and articulated in the trial court would be fed into the Judicial Decision Process without change. However, anyone who has read the differing descriptions of the "facts" in majority and dissenting opinions of appellate courts is well aware that different judges may arrive at different Conclusions about Facts Determined. But such was not the case in De Sylva v. Ballentine. The other justices did not disagree with Justice Harlan's manifest Conclusions about Facts Determined which were: ${ }^{20}$ “. . . an author who secured original copyrights on numerous musical compositions died before the time to apply for renewals arose. He was survived by his widow and one illegitimate child, who are both still living.... The District Court found that the child here was within the terms of [section 255 of the California Probate Code and entitled to inherit his father's estate]." Implicit conclusions about other "facts" must have entered into individual and collective judgment by the Court, however, as it weighed arguments about the economics of the copyright market, probed history for legislative intent, and explored the socioeconomic and ethical rationale of prior judicial opinion.

Rule Selection was also a relatively simple process in this case. The claimants and all Decision Makers agreed that section twenty-four of the Copyright Act was the proper subject for Interpretation. As for the appropriate rules for answering whether "children" as used in section twenty-four includes an illegitimate child, there was considerable difference of opinion between the parties and among members of the Court.

Semantic and Syntactic Rule Interpretation of section twenty-four were so interrelated on the face of the majority opinion that it is not clear whether the Decision Makers ever clearly distinguished the two operations.

Congress used the words "widow, widower, or children." Having done so,

${ }^{10}$ American Society of Composers, Authors and Publishers; Motion Picture Association of America, Inc.; Music Publishers' Protective Association, Inc.; and Songwriters' Protective Association.

$\because$ De s.Sylva v. Ballentine, 35 I.U.S. 570, 572, 581-82 (1956). 
questions of syntax were likely to become an issue for dispute. The court of appeals interpreted the word "or" as meaning "that either one or the other may act for the family which consists of the widow (or widower) and all of the children."21 The widow argued that the court of appeals erroneously substituted a conjunctive "and" for a clear disjunctive "or," and that the Act granted renewal rights to the persons enumerated only in the order of their enumeration. Counsel for the minor child contended that the disputed phrase identifies a class-the entire immediate family of a deceased author, to wit, the widow, widower, or children-to share the renewed copyright as a class.

Agreeing with the parties that the statute was hardly unambiguous, the Court then began to search a broader context for clues in aid of Semantic (and Syntactic) Rule Interpretation. It re-read all of section twenty-four, noting each "and" and "or." In the very next clause of the section, it found an example of that "careless usage" that characterizes much of legislative drafting. It traced renewal rights from the first federal statute (I790) to its present version in title seventeen of the United States Code, noting in detail the various changes in wording and enumeration of persons entitled to renew. It examined administrative practices of the Copyright Office, and the briefs of amici curiae, and writings of specialists on copyright law, The majority opinion reflects little or no satisfaction from any of these sources, and abruptly ceases the fugue of assertion and negation, with the declaration: $:^{22}$ "While the matter is far from clear, we think, on balance, the more likely meaning of the statute to be that adopted by the Court of Appeals ... the widow and children of the author succeed to the right of renewal as a class. ..." In the determination of whether illegitimates are children within the meaning of section twenty-four, Rule Selection and Semantic Rule Interpretation appear to have been concurrent processes. The majority concluded that the federal statute deals with familial relationships, that there is no federal law of domestic relations, and that, therefore, the law of the state which created those relationships should apply. Having selected this rule, it then sought another rule by which to determine which state law defines the legal status of the minor child. Their Conclusions about the Facts Determined resulted in the characterization "the only State concerned is California." 23 Then, reasoning from two premisses-the trial court's finding of "fact" that the illegitimate child in this case was entitled under section 255 of the California Probate Code to inherit his father's estate, and that the copyright renewal provision presents a question of the descent of property ${ }^{24}$-the majority decided that the Ballentine child was included within the term "children" for purposes of a copyright renewal application. Justices Douglas and Black would have selected a different rule by which to

\footnotetext{
"3r. 226 F.2d 623, 628 (9th Cir. 1955).

${ }^{22} 35$ I U.S. 570,580 (1956).

28 ld. at $58 \mathrm{r}$.

: 24 The court of appeals had reasoned from a contrary assumption: "... the right conferred ... is not a renewal or extension of a property which descends in an estate but is a new, personal grant of a right." 226 F.2d 623, 629 (9th Cir. 1955).
} 
determine the (semantic) meaning of the word "children." For them the Relevant Context included preferences for uniformity in the protection of dependents, and, by inference, "humane considerations" and modern social attitudes toward illegitimate children.

De Sylva v. Ballentine illustrates the well known-that judges make many interrelated choices in reaching a decision: factual, normative, semantic, and syntactic. We now shift attention to the latter.

\section{Logic Within the Judicial Decision Process}

From the standpoint of Decision Makers confronted by competing interpretations of ambiguous language, it would appear that a variety of ideas may be expressed in the same way, that is, by the same set of words. However desirable that may be for poetic expressions, this is an absurd state of affairs in the law if it derives from inadvertent syntactic ambiguity.

Let us begin our technical discussion, then, with the quite different observation that the same idea may be expressed in a variety of ways. For example, the sentence "Lawyers draft wills" and the sentence "Wills are drafted by lawyers" express the same idea. The two sentences are even syntactically ambiguous in the same way:

[All/Some] Lawyers draft [all/some] wills.

[All/Some] Wills are drafted by.[all/some] lawyers.

If such syntactic ambiguities are removed, there are several additional ways of expressing the clarified idea. For example, the two sentences:

SI All persons who are lawyers draft some wills. and

S2 If a person is a lawyer, then he drafts some wills.

both express the same idea. If $S_{I}$ were used in a written document, we could substitute $S_{2}$ for $S_{1}$ without changing the ideas expressed by the document. This is no startling revelation, but draftsmen who are aware of the need for rigorously consistent terminology may not be sensitive to a corresponding necessity for standardized syntax. In many contexts, one way of expressing an idea may be more useful than an alternative way; that is, there may be a distinct advantage in adopting one of several altogether permissible ways as a standardized, or "normalized," way of expressing a given idea.

If we wish to express the idea which both $S_{1}$ and $S_{2}$ express, which of these two statements should we choose to express that idea? The answer depends, of course, upon our objectives-the goals we have in mind when we consider the advantages and disadvantages of one or another mode of expression. If one of our goals is to

${ }^{28}$ See quotation from Middleton v. Luckenbach S.S. Co., 70 F.2d 326, 329-30 (2d Cir. 1934), at $35 t$ U.S. 570, 583-84 (1956). 
make the fullest use of computers for purposes of information retrieval (as contrasted with document retrieval), ${ }^{26}$ it will be advantageous to express universal ideas by statements like $S_{2}$, rather than by statements like $S_{r}$. When ideas are expressed by statements like $S_{2}$, much of the logical deduction involved in analyzing that statement and its relation to other statements can be done by means of a computer or some other automatic processing device. ${ }^{27}$ In general, the extent to which deductions can be carried out automatically by an automatic processing device will vary directly with the extent to which the logical relations in a statement are expressed by words that connect complete sentences, rather than by words that connect parts of sentences. Thus, more automatic deduction will be permitted if an idea is expressed by a statement like:

$\mathrm{S}_{3}$ If a member has paid his dues, then he qualifies for benefits; and if a member has a disability, then he qualifies for benefits.

where "if," "then," and "and" connect complete sentences, than if the same idea is expressed by a statement like

$\mathrm{S}_{4}$ Members who have paid their dues and members who have a disability qualify for benefits.

where "and" connects parts of a sentence. Although expressed in still another way,

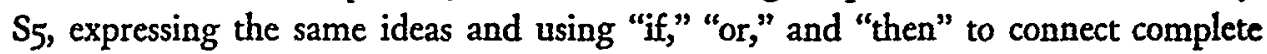
sentences, permits just as much automatic deduction as is permitted by a statement like $S_{3}$.

$\mathrm{S}_{5}$ If a member has paid his dues, or a member has a disability, then he qualifies for benefits. ${ }^{28}$

Thus, if we wish to maximize the potentialities for using automatic processing devices to perform a logical analysis of a document, we need a procedure for transforming statements like $S_{4}$ (involving connections between parts) that are commonly used in legal documents into statements like $S_{3}$ or $S_{5}$ (involving connections between sentences) that express the same idea as that expressed by $\mathrm{S}_{4}$.

so Allen, Beyond Document Retrieval Toward Information Retrieval: Federal Estate Tax (to be published in a fortheoming issue of the Minnesota Law Review).

${ }^{27}$ Tbid.

${ }^{28}$ In $\mathrm{S}_{3}$ the first occurrence of the words "If-then" connects the subsidiary sentence "a member has paid his dues" to the subsidiary sentence "he qualifies for benefits," the second occurrence of the words "if-then" connects the sentence "a member has a disability" to the sentence "he qualifies for benefits"; and, the word "and" connects the sentence "If a member has paid his dues, then he qualifies for benefits" to the sentence "if a member has a disability, then he qualifies for benefits."

In $S_{5}$ the word "or" connects the sentence "a member has paid his dues" to the sentence "a member has a disability" and the words "If-then" connect the sentence "a member has paid his dues, or a member has a disability" to the sentence "he qualifies for benefits."

However, in $\mathrm{S}_{4}$ the word "and" connects the part of a sentence "Members who have paid their dues" to the part of a sentence "members who have a disability."

It should be apparent that there is also a statement that is intermediate between $\mathrm{S}_{4}$ and $\mathrm{S}_{5}$ in the extent to which complete sentences are connected by the words in it that express logical relationsnamely:

S4.5 Members who have paid their dues qualify for benefits, and members who have a disability qualify for benefits. 
There is, however, a complication. Many of the statements in legal writingswhether by design or by accident-are syntactically ambiguous. Instead of a statement like $\mathrm{S}_{4}$, we are more likely to encounter a statement like: $:^{20}$

"Sec. 343. Misbranded Food

"A food shall be deemed to be misbranded-...

"(c) If it is an imitation of another food, unless its label bears, in type of uniform size and prominence, the word 'imitation' and, immediately thereafter, the name of the food imitated."

Is such a statement appropriately interpreted as asserting merely:

(x) If a food, is an imitation of another food, then it shall be deemed to be misbranded if its label does not bear, in type of uniform size and prominence, the word "imitation" and, immediately thereafter, the name of the food imitated;

or is it more appropriately interpreted as asserting:

(2) If a food is an imitation of another food, then it shall be deemed to be misbranded if and only if its label does not bear, in type of uniform size and prominence, the word "imitation" and, immediately thereafter, the name of the food imitated. ${ }^{30}$

This example illustrates a problem frequently encountered in the process of transforming statements written in conventional legal prose into a normalized form that

${ }^{29}$ Federal Food, Drug, and Cosemtic Act of June $25,1938, \S 403,52$ Stat. 1047 (1938), as amended, 67 Stat. 63 I (I953), 2 I U.S.C. $\$ 343$ (I958).

${ }^{30}$ Justice Frankfurter, writing the majority opinion in 62 Cases of Jam et al. v. United States, 340 U.S. 593, 599-600 (195I), seems to favor interpretation (2):

"In ordinary speech there can be no doubt that the product which the United States here secks to condemn is an 'imitation' jam. It looks and tastes like jam; it is unequivocally labeled 'imitation jam.' The Government does not argue that its label in any way falls short of the requirements of ... [ $\$ 343$ (c)]. Its distribution in interstate commerce would therefore clearly seem to be authorized by that section. We could hold it to be 'misbranded' only if we held that a practice Congress authorized by... $[\$ 343(\mathrm{c})]$ Congress impliedly prohibited by ... $[\$ 343(\mathrm{~g})] . "$ The Government was sceking to condemn 62 cases of "Delicious Brand Imitation Jam" for violating $\$ 343(\mathrm{~g})$, claiming that the product purported to be fruit jam although it did not meet the minimum requirements specified in the Federal Security Administrator's promulgated definition of "fruit jam." The section alleged to be violated was added to the Federal Food, Drug and Cosmetic Act in 1938, thirty-two years after enactment of the original Pure Foods and Drug Act. It reads:

"Sec. 348. Misbranded Food.-A food shall be deemed to be misbranded- . . (g) If it purports to be or is represented as a food for which a definition and standard of identity has been prescribed by regulations as provided by $\S 34 \mathrm{I}$ of this title unless ( $\mathrm{I}$ ) it conforms to such definition and standard, and (2) its. label bears the name of the food specified in the definition and standard, and, insofar as may be required by such regulations, the common names of optional ingredients (other than spices, flavoring, and coloring) present in such food." Elsewhere in the opinion, Justice Frankfurter indicates that $\$ 343$ (c) and $\S .343(\mathrm{~g})$ are "apparently conflicting paragraphs," but that even if $\S 343(\mathrm{c})$, which comes from the original Pure Food and Drug Act of 1906, were read as asserting interpretation ( $I$ ), there would still not be any misbranding. He declares: "In ... [\$343(g)] Congress used the words 'purport' and 'represent'-terms suggesting the idea of counterfeit. But the name 'imitation jam' at once connotes precisely what the product is: a different, an inferior preserve, not meeting the defined specifications.... It purports and is represented to be only what it is-an imitation. It does not purport nor represent to be what it is not-the Administrator's genuine 'jam." "Id. at 600. It is to this part of the majority opinion that Justices Douglas and Black express dissent: "... if petitioner's product did not purport to be "jam' petitioner would have no claim to press and the Government no objection to raise." Id. at 6or. 
can be more extensively analyzed by an automatic processing device: the original statement, as written, is ambiguous, and the analyst is faced with choosing whether to leave it ambiguous or to clarify it. If he chooses to clarify it, he must specify which interpretation is most appropriate.

It will prove helpful in detecting possible alternatives to have notational machinery available to use on the statement in its original form to clearly indicate what the various ambiguities are. To a considerable extent, the remainder of this article is devoted to describing and illustrating one method for representing the alternative interpretations of syntactically ambiguous statements. To enhance the probability of detecting such syntactic ambiguities in the analysis of such statements in legal documents, it is useful to examine the statement with an eye to discerning which words are appropriately interpreted as indicating relations between complete sentences, which words are appropriately interpreted as indicating relations between parts of sentences, and just which sentences (or parts of sentences) it is appropriate to interpret such words as relating. In the course of this examination, it is important also to examine the punctuation of a statement and the order in which a statement's parts are arranged to discern what relationships between those parts it is appropriate to interpret the statement as expressing. The results of such analysis can be effectively communicated by means of suitable diagrams, and such diagrams can help revise and improve the drafting of a statement so that it communicates its intended message more effectively. ${ }^{31}$ This procedure involves (a) classification of the various elements of which the statement being analyzed is comprised, (b) tabulating the results of this classification, and (c) constructing diagrams from this tabulation. ${ }^{32}$

\section{A. Sentences, Parts of Sentences, and Their Connecting Words}

In the classification of the elements of a statement it will be useful to distinguish (i) those elements of a statement that are subsidiary sentences, (ii) those elements of a statement that are only parts of sentences, (iii) those elements of a statement that are words that connect subsidiary sentences to other subsidiary sentences, and (iv) those elements of a statement that are words that connect parts of sentences to other parts of sentences. Such a classification of the elements of the following section from the Federal Food, Drug, and Cosmetic Act considered above would begin with the text of the section in question:

To a triple-spaced typewritten copy of the statement to be analyzed:

(i) a line is drawn over each complete subsidiary sentence, and these are labeled in order $\mathrm{S}_{2}, \mathrm{~S}_{2}, \mathrm{~S}_{3}$, and so on;

${ }^{31}$ Although there may be other ways to go about representing the alternative interpretations which may be distinguished in the course of syntactic analysis of any given statement, we have found that a rather simple diagramming technique is quite effective in communicating the results of such analysis. In the course of analyzing legal statements in the drafting stage, such diagrams also help the draftsman to detect unintended ambiguities and often suggest alternative modes of expression that communicate his intention more effectively.

${ }^{32}$ As an analyst gains more experience he may wish to short-cut this procedure by skipping either classification or tabulation, whichever seems more convenient in the particular context. 
Sec. 343 .

SI

A food shell be deemed to be misbranded ......

52

(c) If it is an imitation of another food, unless

s3 its label bears, in type of uniform size and

prominence, the word "imitation and inmediately

thereafter, the name of the food imitated.

(ii) a line is drawn under each element that is only a part of a sentence, and these are labeled $a, b, c$, and so on;

(iii) a rectangular box is drawn around those words that connect complete subsidiary sentences to other complete subsidiary sentences; and

(iv) an oval is drawn around those words that connect parts of sentences to other parts of sentences. ${ }^{33}$

The tabulation of this classification of the elements of section $343(c)$ would appear as follows:

Connecting Words (between sentences)

\section{Sentences}

$1 ;$ Parts of Sentences

$1 \quad 1 \quad 1 \quad$ Connecting Words (between parts)

1 Sr, A food shall be deemed to be misbranded-

If

S2 $_{1}$ it is an imitation of another food,

unless 1

$\mathrm{S}_{3}$ a its label bears,

$b$ in type of uniform

ss The steps in the classification need not be performed in the order specified here. In fact, we have found that most frequently we do them in the following order: (iii), (i), (iv), (ii). However, for some statements, it seems to be convenient to vary this. Each analyst should proceed in the order he finds most convenient. 
c size

and

d prominence,

e the word "imitation"

and,

f immediately thereafter,

$g$ the name of the food imitated.

From this tabulation of section 343 (c) the following diagram can be constructed:

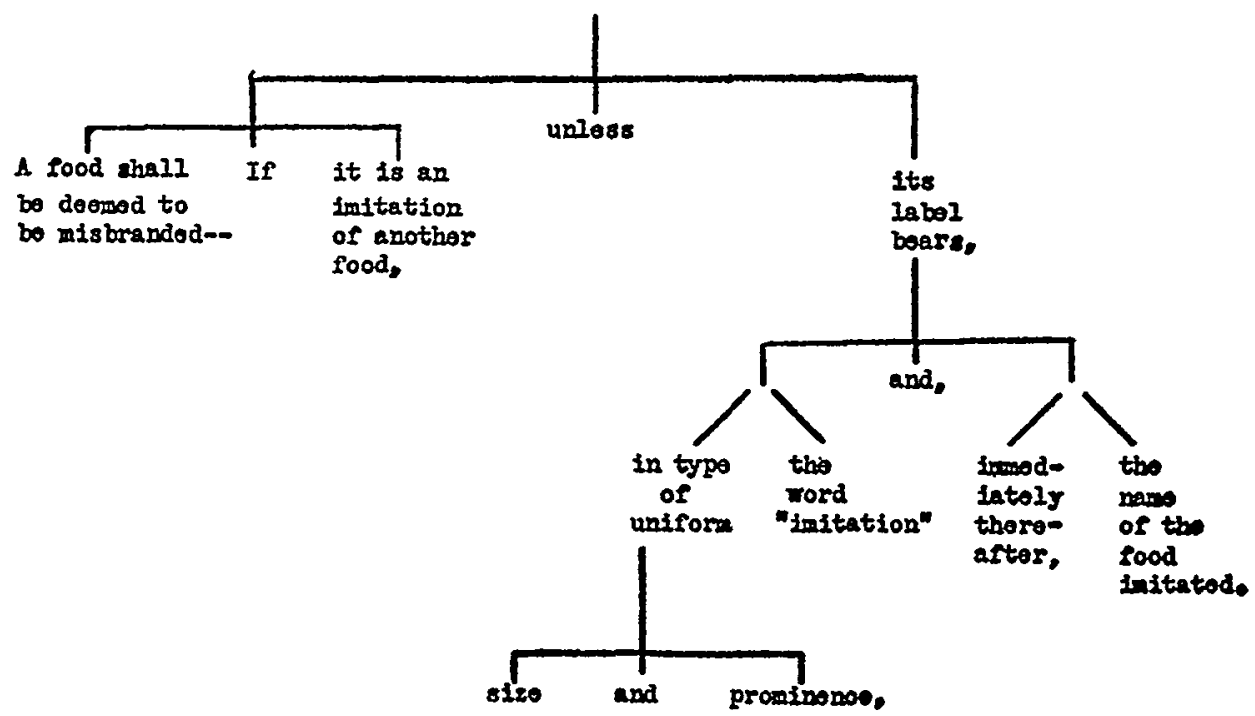

Alternatively, taking advantage of the senterice numbers that have been assigned to the sentences in the statement and the letters that have been assigned to the parts, the diagram can be presented in an abbreviated form such as the following:

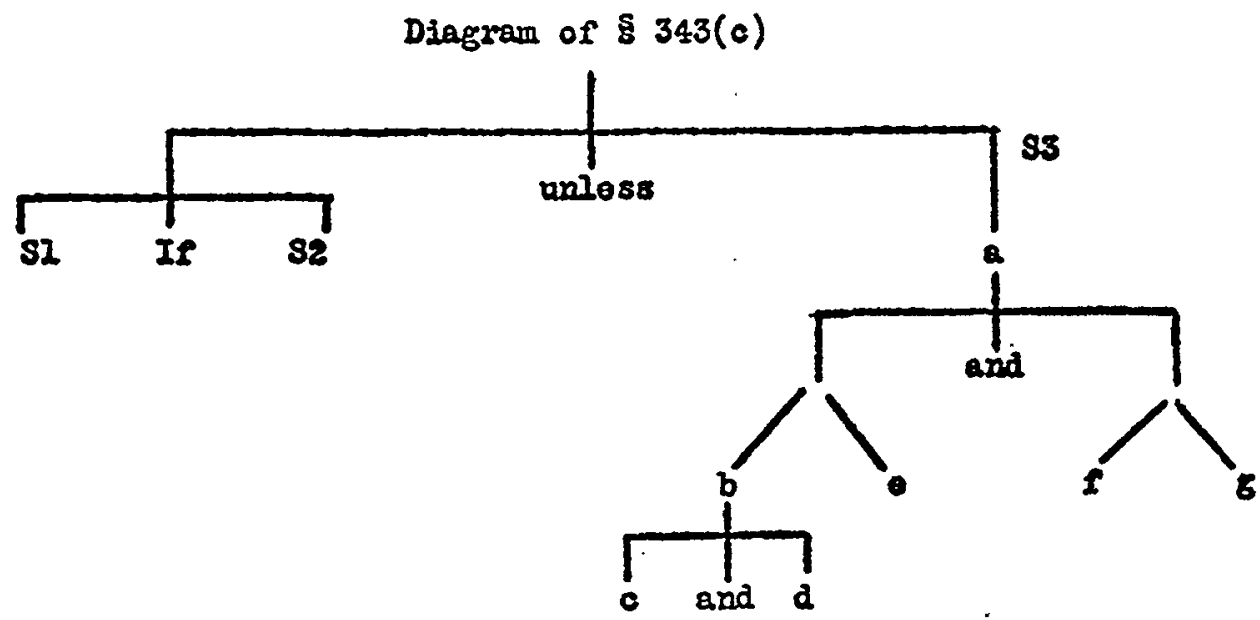


An even more abbreviated diagram of section 343 (c), omitting the detail of the relationships between the parts of $S_{3}$, would be:

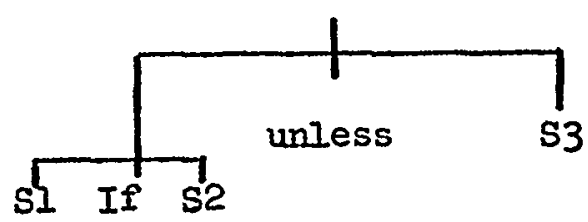

The classification, tabulation, and diagramming of section 343(c) above presents only the results of analyzing that section. In order to do the analysis, we need to specify some criteria for classifying the elements of a statement and to furnish some specifications for constructing the diagrams.

For purposes of classifying the elements of a given statement, the category "subsidiary sentences" refers to those sets of adjoining words in the statement that are complete sentences and are connected to other subsidiary sentences by a word or words.

At the present time, the category "words that connect subsidiary sentences to other subsidiary sentences" refers to words that express logical relations between the ideas expressed by sentences-words such as:

$$
\text { and or if-then if and only if }
$$

or other words that are used to express the same logical relations, words such as:

$\begin{array}{llll}\text { however } & \text { either-or } & \text { when } & \text { except that } \\ \text { but } & & \text { where } & \text { unless } \\ \text { although } & & \text { if } & \text { if }\end{array}$

The category "words that connect parts of sentences to other parts of sentences" refers to the same kinds of words as those for the previous category except that the sets of adjoining words connected by them are something less than complete sentences.

The final category "parts of sentences" is somewhat more vague than the other categories. It refers to sets of adjoining words (perhaps a single word)

-which are not connecting words,

-which are something less than complete sentences, and

-which the analyst perceives that it is useful to designate as parts in order to be able to represent adequately the syntactic relations of the sentence when it is diagrammed. ${ }^{34}$

Thus, which sets of adjoining words are designated as "parts of sentences" will depend explicitly upon the analyst's perception of which ones it is useful to consider to be "parts" for purposes of communicating the various possible syntactic interpretations by diagrams. At one extreme, each word in a sentence that is not a con-

"See note 39 infra. 
necting word might be considered to be a "part of a sentence" in the sense in which that phrase is being used in this article. At the other extreme, a sentence might be regarded as not having any "parts of a sentence" in this stipulated sense; SI and S2 in section 343 (c) are examples of such sentences. ${ }^{35}$

Although these criteria for classifying the elements of a given statement are still so vague that it is improbable that a group of four or five analysts would initially arrive at the same classification, the criteria are nevertheless sufficiently precise to enable each analyist to justify why he chose his particular classification. If the classification adopted by one analyst permits the representation of an ambiguity that the classification of the others does not, he has available efficient communication tools to make it apparent that this is so. The relations between various subsidiary sentences and parts of sentences contained in a given statement.can be indicated by appropriate diagrams. We now turn to a consideration of how such diagrams are to be constructed.

In general, we wish the diagrams to present exactly the same words that have appeared in the original statement in exactly the same order. Although the original statement may be ambiguous (in varying degrees) with respect to the syntactic relations expressed, the diagrams are intended to furnish a means of expressing each of the possible syntactic interpretations of the statement unambiguously. With most statements it will be possible to maintain this exact correspondence between the words used in, and the word-order of, the original statement; and the words used in, and the word-order of, the diagram. However, occasionally (and section 343 (c) may be an example of this) it may become necessary to shift the word-order of the original statement in order to represent adequately by the diagram the interpretation of the original statement that-from the total context-seems appropriate.

In order to achieve a correspondence in the word-order of statements and diagrams, it is necessary to specify some ordering principles for the diagrams used in this article. Statements are read from left to right and from top to bottom; in general, the diagrams used here are to be ordered similarly-but with some qualifications. It is useful to consider diagrams as divided into five units: upper-middle units, middlemiddle units, left units, lower middle units and right units. These are labeled UM, $M M, L, L M$, and $R$, respectively, in diagram $I$.

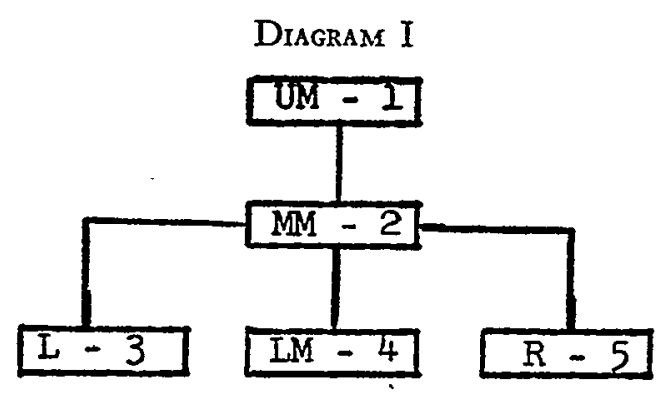

${ }^{a b}$ See p. 238 , supre. 
Any one or more of these units may not occur in a particular diagram, but those that are present are to be read in the order in which the units are numbered-namely: UM-I, MM-2, L-3, LM-4, and R-5.

The element of a statement that appears in the UM unit of a diagram will always be a part of a sentence; it will never be a connecting word, and it will never be a subsidiary sentence. The elements of a statement that appear in the MM and LM parts of a diagram will always be connecting words-either words that connect subsidiary sentences to subsidiary sentences or words that connect parts of sentences to parts of sentences. The elements of a statement that appear in the $L$ and $R$ units of a diagram will always be subsidiary sentences or parts of subsidiary sentences.

It may be useful to consider a few examples to illustrate the ordering and classification of various elements of a statement as they appear in a diagram. The state ment:

(I) If lawyers toil, then clients benefit. would be represented by the diagram:

$\left(D_{I}\right)$

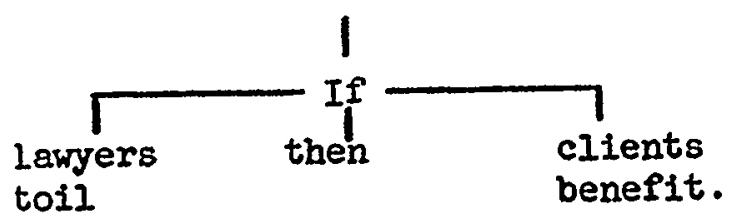

However, the following statement, which uses different words (it does not use "then") in a different order, expresses the same idea:

(2) Clients benefit, if lawyers toil.

It would be represented by the diagram:

(D2)

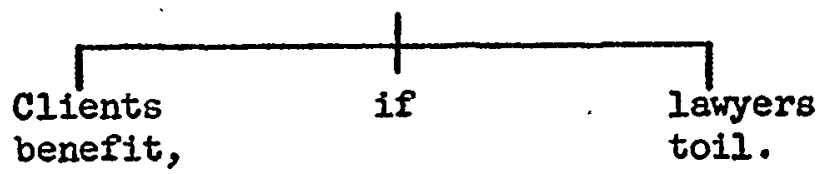

And the yet different statement (still expressing the same idea)

(3) If lawyers toil, clients benefit. would be represented by the diagram:

$\left(D_{3}\right)$

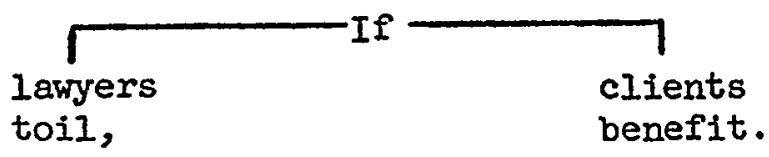

Note the differences between $\left(D_{2}\right)$ and $\left(D_{3}\right)$. The "if" in $\left(D_{2}\right)$ appears as the LM unit of the diagram; the "if" in $\left(D_{3}\right)$ appears as the MM unit. The subsidiary 
sentences appearing as the $L$ and $R$ units, respectively, of (D2) appear as the $R$ and $L$ units, respectively, of $\left(D_{3}\right)$; and vice versa. In these examples, $\left(D_{2}\right)$ and $\left(D_{3}\right)$ express the same idea; and more generally regardless of what sentences are represented by $\mathrm{S}_{1}$ and $\mathrm{S}_{2}$, it will always be the case that the diagram:

$\left(\mathrm{D}_{4}\right)$

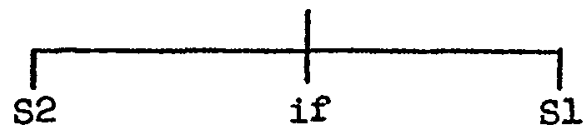

will express the same idea as the diagram:

$\left(D_{5}\right)$

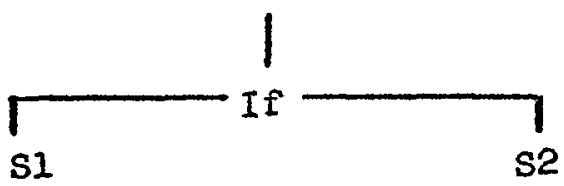

And without changing the idea expressed, both a diagram like $\left(D_{4}\right)$ and one like (D) can be transformed into the diagram:

(D6)

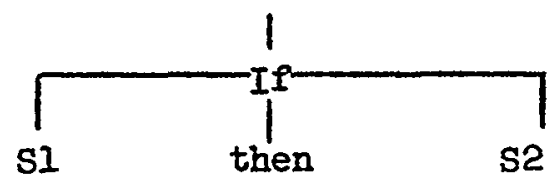

The $L$ and $R$ units of a diagram may, in turn, contain subsidiary $U M, M M, L$, $L M$, and $R$ units which will be read in the same order as that specified for the previous $U M, M M, L, L M$, and $R$ units. And, again in turn, the $L$ and $R$ units of these $L$ and $R$ units may themselves have subsidiary $U M, M M, L, L M$, and $R$ units, and so on. For example, consider the statement:

(7) If lawyers loaf, then clients suffer, and clients complain. which might be represented by the diagram:

(D7.I)

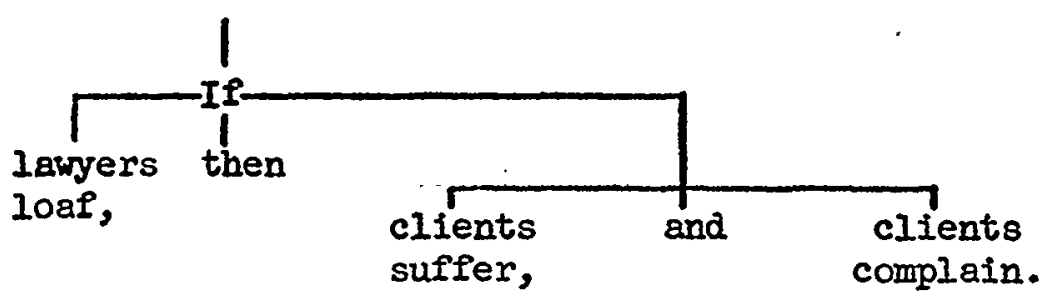

On the other hand, it might be more appropriate to represent (7) by the diagram: 
$\left(D_{72}\right)$

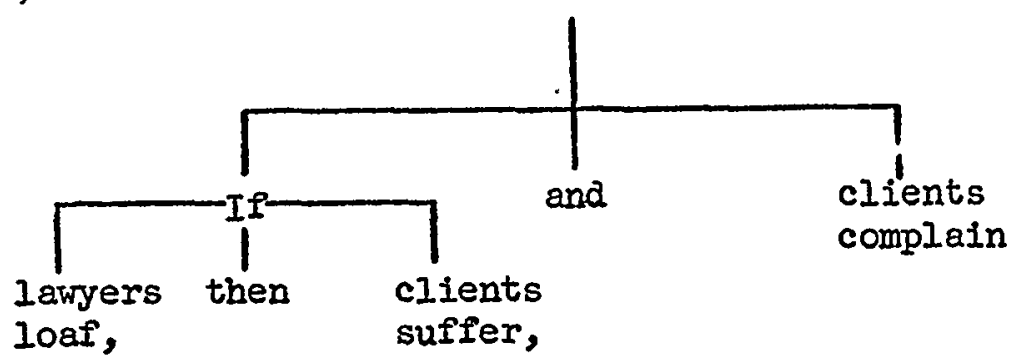

Without more context to furnish some guidance, statement (7) is ambiguous. It is not clear whether ( 7 ) is intended to assert merely that clients complain when lawyers loaf (in which case (D7.I) is the appropriate diagram) or whether it is intended to assert that clients always complain-whether or not lawyers loaf (in which case $\left(D_{7.2}\right)$ is the appropriate diagram) ${ }^{36}$

The subsidiary $L$ and $R$ units in the $R$ unit of $\left(D_{7} .1\right)$ and the $L$ unit of $\left(D_{7} .2\right)$, respectively, represent subsidiary sentences of $(7)$. Such subsidiary units may also represent parts of sentences, e.g., the parts of sentences represented by the $\mathrm{L}$ unit (b-c-d-e) and the $R$ unit ( $f-g$ ) of $S_{3}$ of section $343(c){ }^{37}$

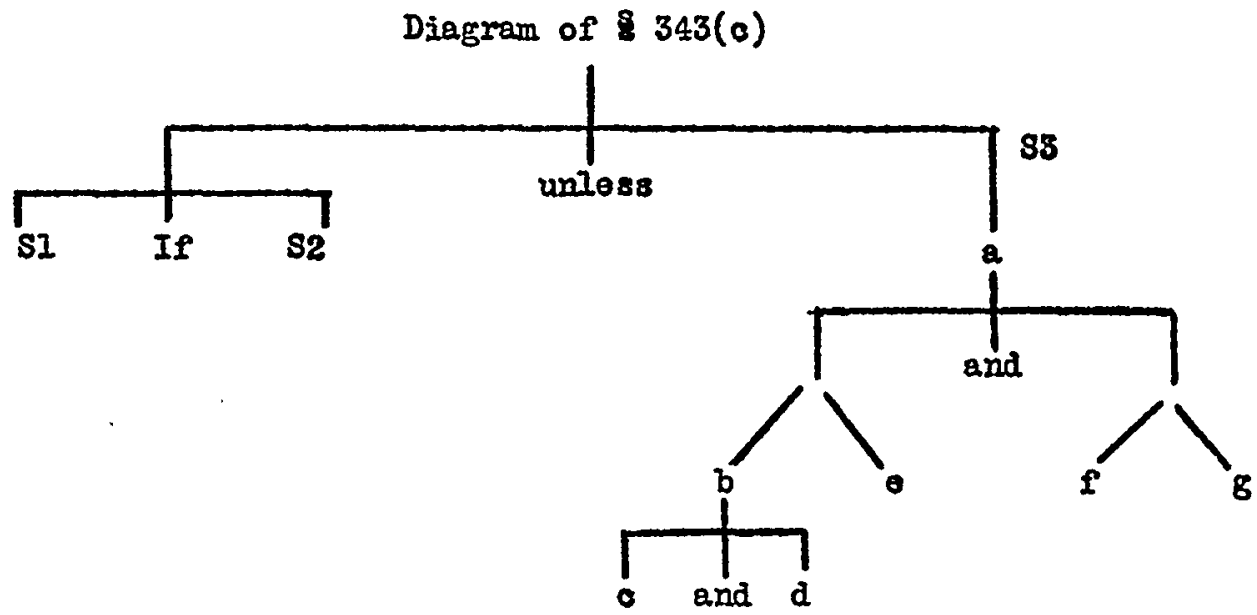

${ }^{36}$ Of course, the syntactic ambiguity in (7) can be clarified by punctuation:

(7.1) If lawyers loaf, then clients suffer and clients complain. for (D7.r) and

(7.2) If lawyers loaf, then clients suffer; and clients complain. for (D7.2).

However, there are other cases of syntactic ambiguity in ordinary prose for which customary punctuntion is ineffective.

${ }^{37}$ For example, LL is the left subsidiary unit of the $\mathrm{L}$ unit, and RLR is the right subsidiary unit of the left subsidiary unit of the $R$ unit:

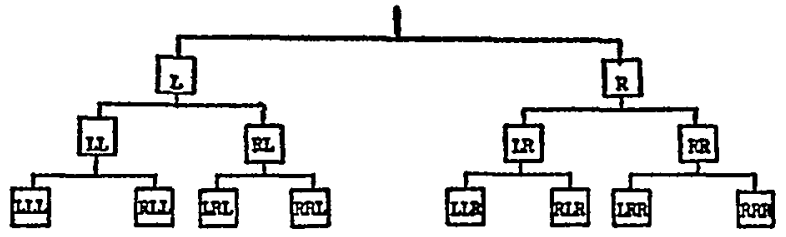


Since $S_{3}$ is represented by the $R$ unit of the diagram of section 343 (c), b-c-d-e is represented by the subsidiary $L$ unit of the $R$ unit of the diagram, and $f-g$ is represented by the subsidiary $R$ unit of the $R$ unit of that diagram. Similarly, $b-c-d$ is the subsidiary $L$ unit of the subsidiary $L$ unit of the $R$ unit; $e$ is the subsidiary $R$ unit of the subsidiary $L$ unit of the $R$ unit; $f$ is the subsidiary $L$ unit of the subsidiary $R$ unit of the $R$ unit; and $g$ is the subsidiary $R$ unit of the subsidiary $R$ unit of the $R$ unit of the diagram of section 343 (c).

In the course of illustrating the ordering and classifying of the various units and connecting words of a diagram which represent the elements of a statement, we have encountered one kind of syntactic ambiguity-namely, the ambiguity involved when it is unclear just which two subsidiary sentences a sentence-connecting word is intended to connect. Other kinds of ambiguity also need to be considered. One important kind of ambiguity is concerned with how it is appropriate to interpret words such as:

if or unless except when

Another significant kind of ambiguity is concerned with how it is appropriate to interpret the juxtaposition of parts of sentences in a statement.

The problem of representing by diagrams the interpretation of what relation the word "if" and other similar words express is illustrated by (2). By uttering the statement:

(2) Clients benefit, if lawyers toil.

has one asserted:

(8) If lawyers do not toil, then clients do not benefit.

In other words, is (2) appropriately interpreted as asserting merely:

(9) Clients benefit, if lawyers toil (without suggesting that lawyers toil, if clients benefit).

or is (2) more appropriately interpreted as asserting:

(ro) Clients benefit, if and only if, lawyers toil.

Which interpretation is appropriate will depend, of course, upon the context in which the statement is used. To communicate effectively what alternatives are perceived, we need notational devices that will enable us to diagram statement (2) so as to distinguish clearly between interpreting it as expressing merely statement (9) and interpreting it as expressing statement (1o). Diagram $\left(\mathrm{D}_{2}\right)^{38}$ is the appropriate interpretation of (2), only if we wish to remain ambiguous about how the "if" is being interpreted. If we wish to indicate clearly that the "if" is appropriately interpreted as expressing only an "if-then" (implicative) relation between the sentences

\footnotetext{
${ }^{88}$ At p. 242, supra.
} 
it connects, then we shall add one asterisk to the left of the "if" in the diagram. Thus, the diagram:

(D2.I)

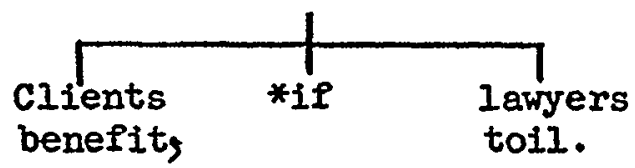

indicates that (2) asserts (9). On the other hand, if we wish to indicate clearly that the "if" is appropriately interpreted as expressing an "if and only if" (coimplicative) relation between the sentences it connects, then we shall add two asterisks to the diagram-one to the left of the "if" and one to the right. Thus the diagram:

$\left(D_{2.2}\right)$

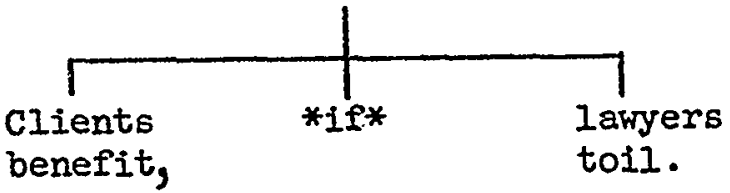

indicates that (2) asserts (10).

Returning to the question asked originally about section $343(c)$-whether $(x)$ an imitation food is misbranded if it is not clearly labeled or (2) it is misbranded if and only if it is not clearly labeled-we now have enough notation available to indicate unambiguously by means of diagrams the various alternative interpretations. The "if-then ... not" interpretation of the "unless" in section 343 (c) would be represented by the diagram:

$(\mathrm{D} \S 343(\mathrm{c}) \cdot \mathrm{x})$

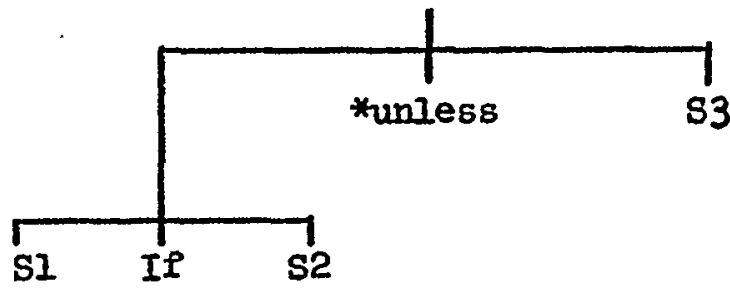

while the "if and only if ... not" interpretation of the "unless" would be represented by the diagram:

(D $\S 343(c) .2$ )

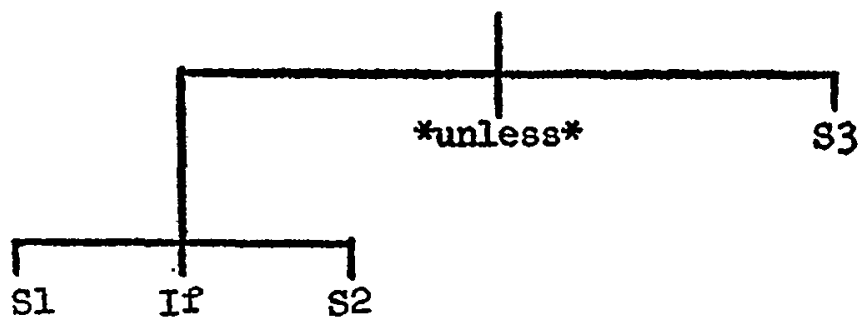


The problem of representing by diagrams the various interpretations of sentences that contain various juxtaposed parts of sentences is illustrated by the statement:

(II)

$$
\frac{\text { He wore }}{\mathrm{a}} \frac{\mathrm{a}}{\mathrm{b}} \frac{\text { light }}{\mathrm{c}} \frac{\mathrm{green}}{\mathrm{d}} \frac{\text { suit }}{\mathrm{e}} \text { to the game. }
$$

The ambiguity in (Ir) centers around what word or words the word "light" is to be interpreted as qualifying. Was the suit in question:

(A) light green in color (but possibly heavy in weight)?

(B) light in weight and green in color (but possibly dark green)?

(C) light in weight and light green in color?

A suit of Type $A$ would be indicated by the diagram:

(Drx.r)

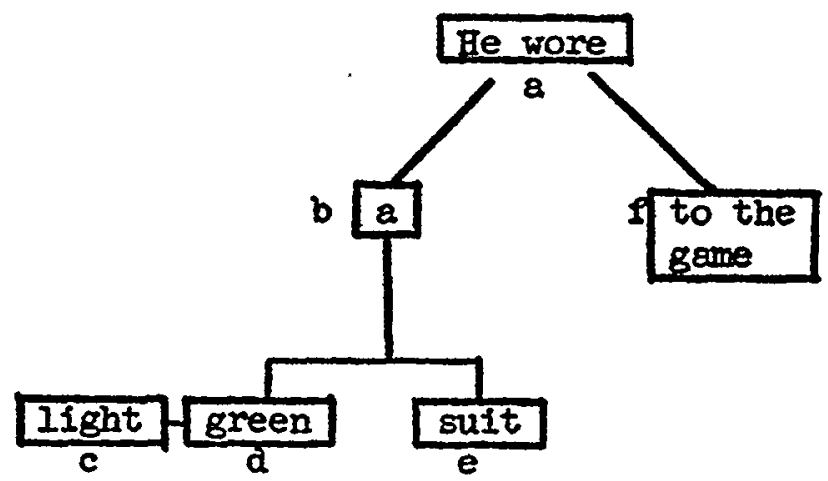

A suit of type B would be indicated by the diagram:

(Drr2)

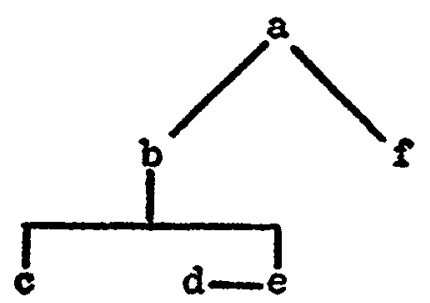

And a suit of type $\mathrm{C}$ would be indicated by the diagram:

(Drr.3)

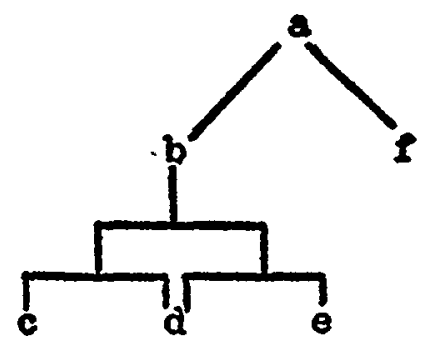


The diagrams for representing the parts of sentences that are related by juxtaposition are slightly different from the diagrams that represent parts of sentences related by connecting words, and some additional criteria for ordering the parts related by juxtaposition are needed. There are no MM and LM units in diagrams for representing parts of sentences that are related by juxtaposition, but the other units are ordered the same way as are the units in diagrams for parts of sentences that are related by connecting words, that is:

(DI2)

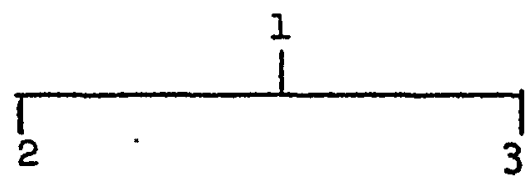

There is a similar, but slightly different, diagram for parts of sentences that are related by juxtaposition. It is ordered as follows:

(Dr3)

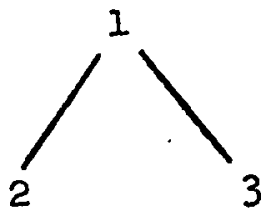

And finally, there are diagrams for parts of sentences that are related by juxtaposition whose parts are ordered as shown in the following pair of diagrams:

(Dr4)

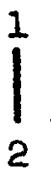

(Dr5)

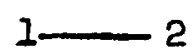

For any three juxtaposed parts (or combinations of parts) of sentences, there seem to be exactly fourteen ways that these parts may be syntactically related. ${ }^{30}$ We shall need a different way of representing each of these fourteen different

${ }^{30}$ The relationship between "parts of a sentence," "combinations of parts of a sentence," and "qualifying" (as the three terms are used in this article) can be stated:

(a) If a set of words is a combination of parts of a sentence, and that combination is not a sentence, then that set of words is a part of the sentence; and

(b) two parts of a sentence form a combination of parts of the sentence if and only if they qualify each other. 
syntactic interpretations of three juxtaposed parts (or combinations). For example, consider a sentence comprised of the three parts: $\mathrm{x}, \mathrm{y}$, and $\mathrm{z}$.

To indicate that:

let us use:

the $x$ part qualifies the $y$ part

(xy) I

the $\mathrm{x}$ part does not qualify the $\mathrm{y}$ part

the $x$ part qualifies the $z$ part

(xy) 0

the $\mathrm{x}$ part does not qualify the $\mathrm{z}$ part

(xz) I

the $y$ part qualifies the $z$ part

(xz) 0

(yz) I

the y part does not qualify the $z$ part

(yz) 0

the $\mathrm{x}$ part qualifies the $(\mathrm{yz})$ combination

$\mathrm{x}(\mathrm{yz}) \mathrm{I}$

the $x$ part does not qualify the $(y z)$ combination

$x(y z) \quad 0$

the $z$ part qualifies the $(x y)$ combination

(xy) z I

the $\mathrm{z}$ part does not qualify the (xy) combination

$(x y) z 0$

Using these abbreviations, by:

$\frac{(x y)}{I} \frac{(x z)}{0} \frac{(y z)}{I} \frac{x(y z)}{I} \frac{(x y) z}{0}$

we can indicate the interpretation of sentence $x-y-z$ which asserts:

(A) the $x$ part qualifies the $y$ part,

(B) the $\mathrm{x}$ part does not qualify the $\mathrm{z}$ part,

(C) the y part qualifies the $z$ part,

(D) the $x$ part qualifies the (yz) combination, and

(E) the $z$ part does not qualify the (xy) combination.

This interpretation of sentence $x-y-z$ can be represented by the diagram:

$(\mathrm{Di} 6)$

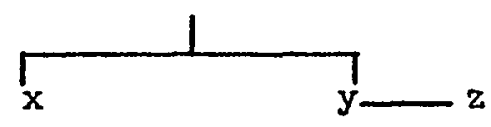

Notice in (DI6) that there is a line which connects every part and every combination to each part or combination that it qualifies:

-- the line "

the $x$ part to the $y$ part and the

$x$ part to the (yz) combination; and

-- the line "س" connects the y part

to the $z$ part. 
If (Di6) is modified slightly so that the line from the $x$ part connects to the $z$ part, a different interpretation is indicated by the resulting diagram:

$\left(\mathrm{D}_{\mathrm{i} 7}\right)$

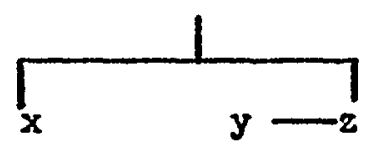

The interpretation that $\left(\mathrm{D}_{\mathrm{I}}\right)$ represents is:

$$
\frac{(x y)}{0} \frac{(x z)}{I} \frac{(y z)}{I} \frac{x(y z)}{I} \frac{(x y) z}{0}
$$

The interpretation which is the same as that represented by $\left(D_{17}\right)$, except that the $\mathrm{x}$ part does not qualify the $\mathrm{z}$ part, would be:

$$
\frac{(x y)}{0} \frac{(x z)}{0} \frac{(y z)}{I} \frac{x(y z)}{I} \frac{(x y) z}{0}
$$

and it would be represented by the diagram:

(Dr8)

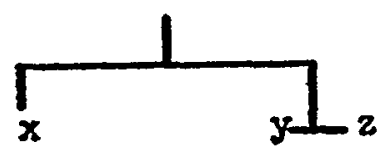

The interpretation which is the same as that represented by (Dr7), except that the $x$ part does not. qualify the $(y z)$ combination, would be:

$$
\frac{(x y)}{0} \frac{(x z)}{I} \frac{(y z)}{I} \frac{x(y z)}{0} \frac{(x y) z}{0}
$$

and it would be represented by the diagram:

(Drg)

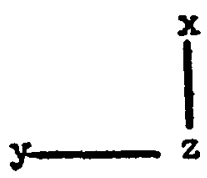

These four examples illustrate most of the notational devices that are used in the fourteen different diagrams that are stipulated here to represent the fourteen different possible syntactic interpretations of the three juxtaposed parts of a sentence. The fourteen different interpretations, and the diagrams that represent them, are presented in table one. 
TABLE I

\section{Interpretation}

Diagram

$\begin{array}{llllll}\# & (x y) & (x z) & (y z) & x(y z) & (x y) z\end{array}$

$\begin{array}{llllll}1 & 1 & 1 & 0 & 0 & 0\end{array}$

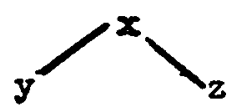

21

0

1

0

o

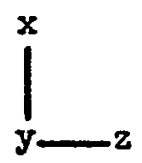

$\begin{array}{lllll}3 & 0 & 1 & 1 & 0\end{array}$

0

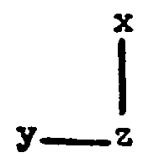

41

1

1

0

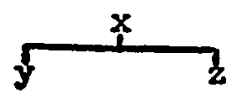

50

0

1

1

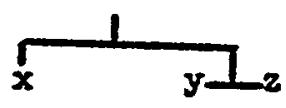

61

0

2

1

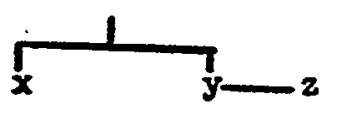

70

1

1

2

0

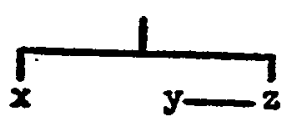


TABLE I-Continued

\section{Interpretation}

\section{Diagram}

$\# \quad(x y) \quad(x z) \quad(y z) \quad x(y z) \quad(x y) z$

$\begin{array}{llllll}8 & 1 & 1 & 1 & 1 & 0\end{array}$

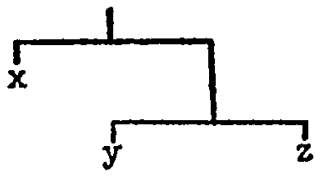

91

0

0

0

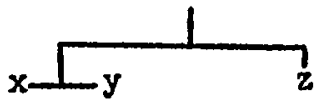

201

1

0

0

1

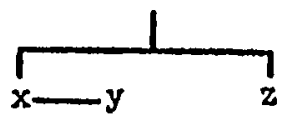

111

0

1

0

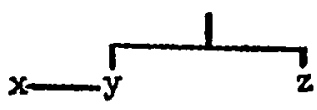

121

1

10

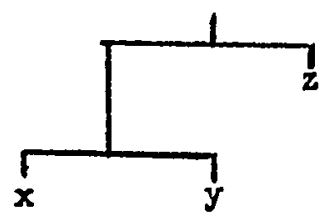

131

0

1

2

1

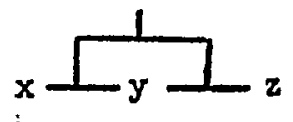

$\begin{array}{llllll}14 & 1 & 1 & 1 & 1\end{array}$

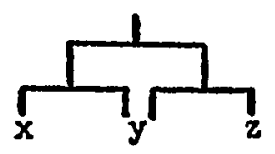


B. Examples of Elements Connected by Connecting Words

Frequently statements in ordinary language are ambiguous about just which sentences (or parts of sentences) a given connecting word (or words) should be interpreted as connecting. Because of this ambiguity in ordinary language, some additional refinement of the notation that is set forth in table one is necessary. This refinement will be added in the course of considering some examples. Consider the statement:

(20) Persons can be nominated for appointment to the board of directors by a a petition from one-sixth of the electors from district one and district two to the chairman.

e

Which of the following should (20) be interpreted as asserting?

(20.I) Persons can be nominated for appointment to the board of directors by a petition from one-sixth of the electors from district one to the chairman, and persons can be nominated for appointment to the board of directors by a petition from one-sixth of the electors from district two to the chairman. ${ }^{40}$

(20.2) Persons can be nominated for appointment to the board of directors by a petition from one-sixth of the electors from district one and one-sixth of the electors from district two to the chairman.

(20.3) Persons can be nominated for appointment to the board of directors by a petition from one-sixth of the electors from district one and district two combined to the chairman.

An ambiguous representation of statement (20), not clearly specifying what the word "and" is intended to connect to what, is presented in the diagram:

(D20)

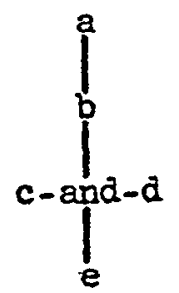

Alternatively, a representation that is ambiguous about how the units a and $e$ are related to the other units is presented in the diagram:

(D20a)

\section{$a-b-c-a n d-d-e$}

${ }^{10}$ The underlined parts in (20.1), (20.2), and (20.3) are words that have been added to the original statement. 
However, if we wish to indicate unambiguously that (20) is appropriately interpreted as asserting (20.x), then we can use diagram: $:^{41}$

(D20.x)

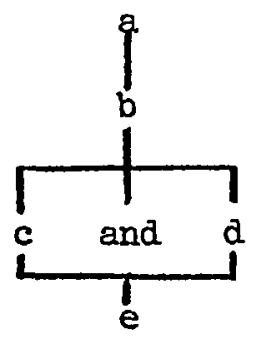

That (20) is appropriately interpreted as asserting (20.2) is represented by the diagram: $:^{2}$

(D202)

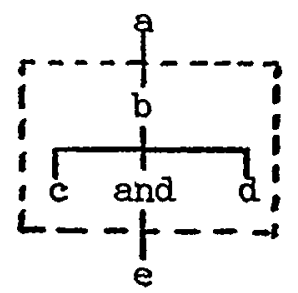

And finally, the unambiguous, representation of (20) interpreted as asserting (20.3) would be represented by the diagram: $:^{43}$

(D20.3)

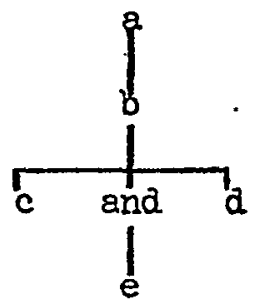

“The " of (D20.r) indicates that (D20.1) asserts "(a-b-c-c)-and-(a-b-d-c)."

"The "

"s The "

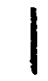


It is important to notice that (D20.I) and (D20.3) are the "extremes" with respect to what units the "and" is interpreted as connecting. (D20.x) indicates "(a-b-c-e)and-(a-b-d-e)," while (D20.3) indicates "a-b-(c-and-d)-e." Since the "and" in diagrams like ( $D_{20.1)}$ indicates a connecting word that connects units that represent complete sentences constructed from parts of the subsidiary sentence in which the "and" originally appears, such an "and" will be referred to as a sentence-unit connecting word. The "and" in diagrams like ( $\mathrm{D}_{20.3)}$ indicates a connecting word that connects only the units that represent the parts immediately adjacent to that "and" in the subsidiary sentence in which it originally appears, and this kind of "and" will be referred to as a minimum-unit connecting word.

An intermediate position between these two extremes with respect to what units the "and" is interpreted as connecting is expressed by (D20.2). The "and" in a diagram like ( $\mathrm{D}_{20.2)}$ will be referred to as an intermediate-unit connecting word. (D20.2) indicates "a-((b-c)-and-(b-d))-e." The dotted lines indicate which other units (in this case, just unit b) are to be included along with the immediately adjacent units in the combinations that the connecting word is to be interpreted as connecting. Thus, if the dotted line also encompasses unit $\mathrm{e}-\mathrm{as}$ in diagram:

(D20.4)

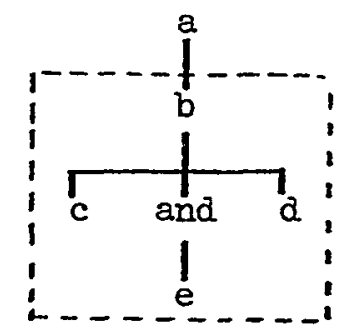

the interpretation of (20) indicated is "a-((b-c-e)-and-(b-d-e))." However, for this example we do not need (D20.4), because; if (D20.2) and (D20.4)-along with the sentences that they represent-are examined carefully, it is evident that both of the sentences represented by these two diagrams express the same idea. These two diagrams represent interpretations of (20) that are equivalent to each other in meaning. Thus, only one of these diagrams involving an intermediate-unit "and" is needed along with the two extremes to express all the different syntactic interpretations of (20). In fact, it will be relatively rare that any diagrams involving intermediate-unit connecting words will be necessary, because it is usually the case that one of the extreme diagrams-either one with the sentence-unit connecting word or one with the minimum-unit connecting word-will represent an interpretation that is equivalent in meaning to the interpretation represented by any diagram with an intermediate-unit connecting word. For example consider the statement:

(20a) $\frac{\text { Persons with residences in New York }}{\mathrm{a}} \frac{\text { and } \frac{\text { Florida }}{\mathrm{c}}}{\mathrm{d}} \mathrm{have \text {standingtosue. }}$ 
The interpretation represented by the diagram with the sentence-unit connecting word: $:^{44}$

(D20a.I)

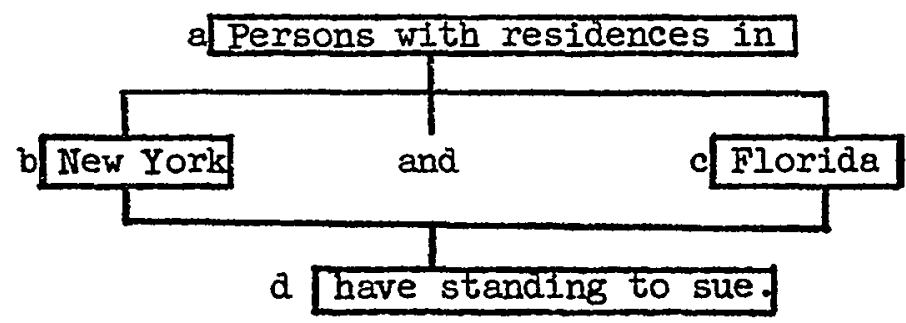

expresses a different idea from that expressed by the interpretation represented by the diagram with the minimum-unit connecting word: ${ }^{45}$

(D20.a.2)

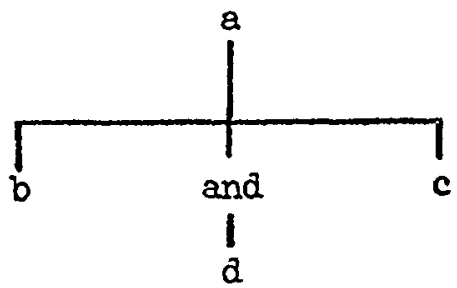

But the interpretation represented by the diagram with the intermediate-unit connecting word: $:^{18}$

(D20a.3)

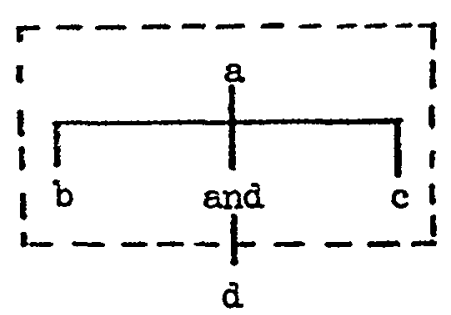

expresses the same idea as that expressed by the interpretation represented by (D20a.I). Therefore, (D20a.3) is not needed to distinguish all of the different interpretations of (20a); (D20a.I) can be used to represent the interpretation which expresses the idea expressed by the interpretation that (D20a.3) represents.

Occasionally, however, diagrams with intermediate-unit connecting words will be needed. An example is the following statement in section 75 of chapter 122 of the Illinois Revised Statutes, Ig6r, the interpretation of which was an issue in Hailey v. County Bd. of School Trustees of Tazewell County: $:^{\text {"7 }}$

\footnotetext{
"4 (D20a.x) asserts "( $a-b-d)$-and-(a-c-d)."

${ }^{45}$ (D20a.2) asserts "a-(b-and-c)-d."

${ }^{46}$ (D20a.3) asserts "( (a-b)-and-(a-c))-d."

17 21 IIl. App.2d 105, 157 N.E.2d 570 (1959).
} 
(2I)

\author{
SI \\ If there is a recognized school district wich as a \\ result of detachment is without a school building, the \\ detachment may be set aside by the county board of school \\ trustees of the county over which the county superintend- \\ ent of schools had supervision and control prior to the \\ detachment upon petition by tho-thirds of the eligible \\ voters in the school district after such detachment and \\ the detached area.
}

The plaintiffs, arguing that a petition to set aside a detachment was insufficient, claimed that the appropriate interpretation of (2I) is:

(2x.I) . . . two-thirds of the eligible voters in the school district after such detachment and two-thirds of the eligible voters in the detached area.

that is, the interpretation represented by the diagram:

(D2r.I)

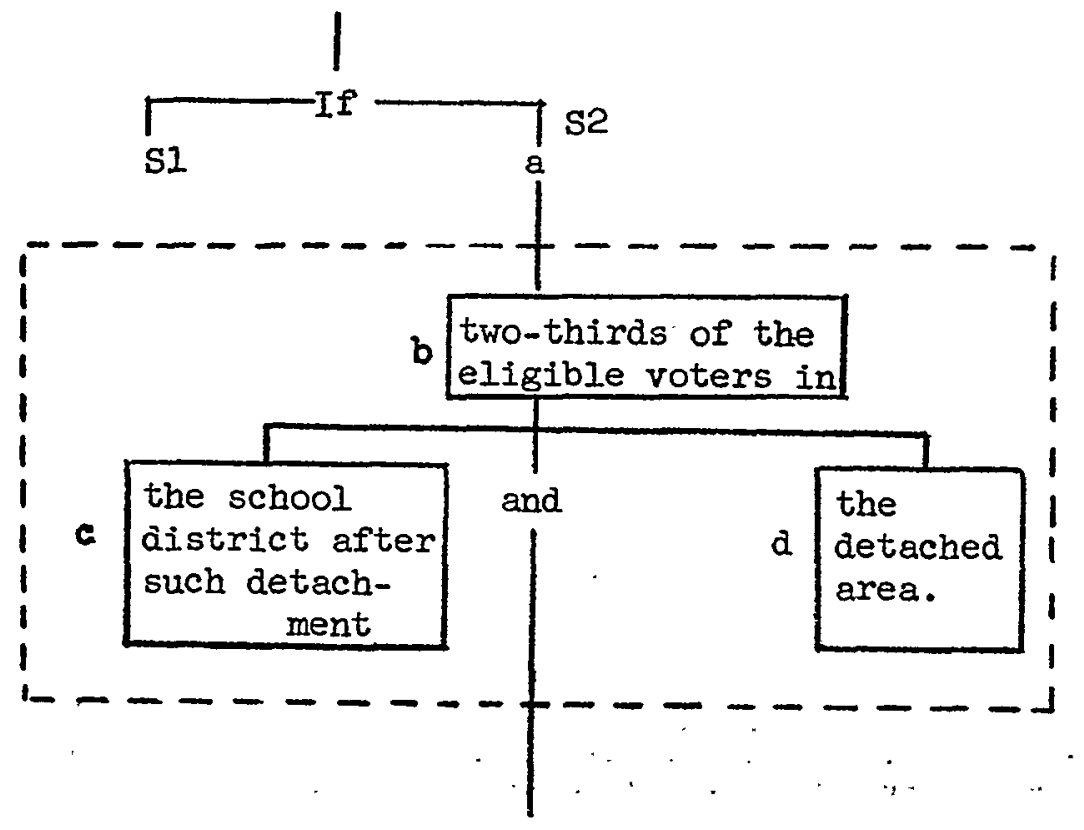


The court, however, held unanimously that the appropriate interpretation of (2x) is:

(2I.2) ... two-thirds of the eligible voters in the school district after detachment and the detached area combined.

that is, in effect two-thirds of the eligible voters in the area which was the district before detachment. ${ }^{48}$ The court's interpretation is represented by the diagram:

(D2I.2)

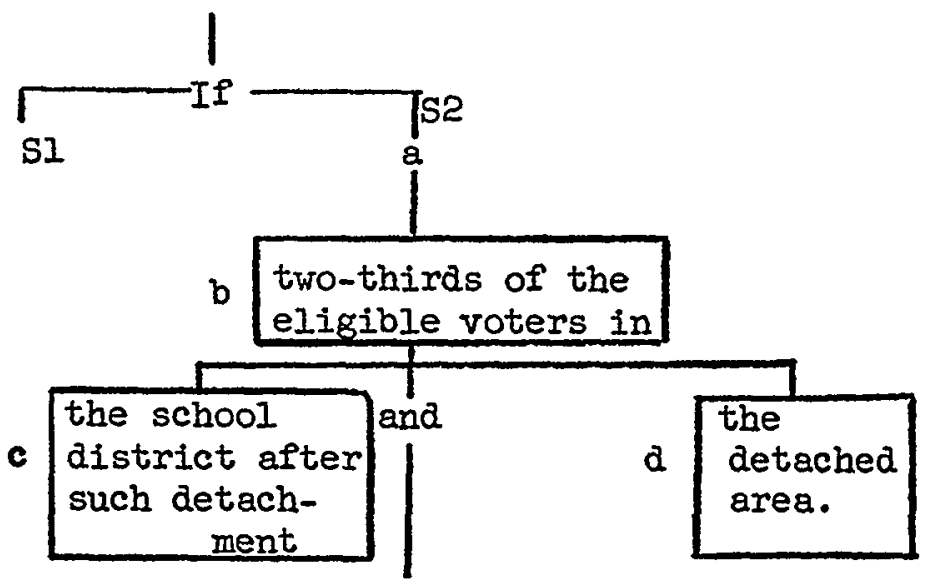

There was no discussion in the opinion of a third interpretation-the one represented by the diagram:

(D2I.3)

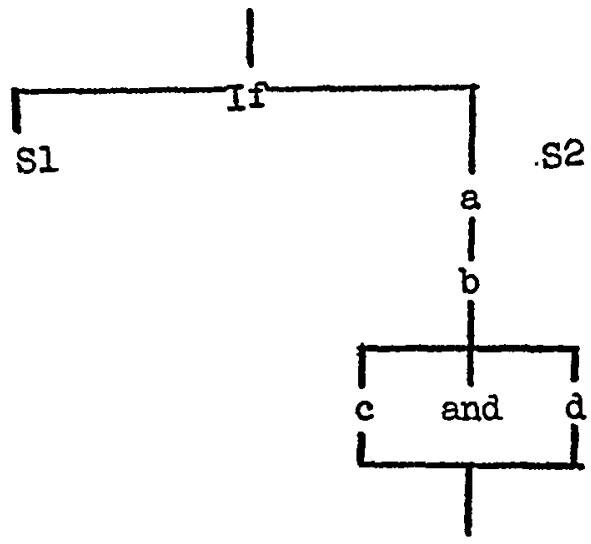

It seems absolutely clear from the total context in which (20) appears that this third interpretation is not what is intended by the statement.

However, in many cases the courts do, in effect, interpret an "and" as a sentence- 48 "The language is plain, clear and unambiguous. It requires a petition of two-thirds of the eligible voters in the area not detached and the area detached, or in other words, two-thirds of the voters in the district before detachment." 21 Ill. App.2d 105, III, I57 N.E.2d 570, 574 (1959). 
unit connecting word. When judges decide, in effect, that the sentence-unit interpretation of "and" is the appropriate interpretation, they frequently declare that they are interpreting the "and" as an "or," rather than discuss the kind of "and" that is involved and what sentences it connects. For example, in Geyer v. Bookwalter," one question presented involved interpretation of the following provision in a decedent's will:

(22) To my wife, Beulah M. Geyer, 1 give and devise the home place at 3 I7 Patterson Street in Neosho, Missouri .... She shall have good and full a

right to sell and convey fee simple title thereto, with such easements as are appurtenant, and not account for the proceeds thereof.

In determining the federal estate tax consequences of this transfer to the wife, a question presented for decision was whether this provision gave the wife only a power to convey the property by virtue of a sale or whether it gave her an interest that was entitled to more favorable tax treatment-that is, an interest which included the power to dispose of the property by gift. The decision turned on the interpretation of the "and" between "sell" and "convey." In deciding in favor of the taxpayer, the court said:50 "In order to effectuate the intention of this testator, the word 'and' is to be construed to mean "or." In terms of the analysis presented in this article, the court, in effect, interpreted the "and" as a sentence-unit connecting "and," rather than a minimum-unit connecting "and." The court accepted the interpretation represented by the diagram: ${ }^{51}$

193 F. Supp. 57, 59 (W.D. Mo. I96r).

cold. at 62 .

${ }^{B 2}\left(D_{22.1}\right)$ asserts " ((a-b-d)-and-(a-c-d))-and $d-(a-c) . "$ 
(D22.I)

a

She shall have good and full right to

a

fee simple title thereto, $\mathrm{b}$ se11 and convey

and

ith such easements as are appurtenant,

not account

e for the pro-

ceeds thereof

and rejected the interpretation represented by the diagram: $:^{62}$

(D22.2)

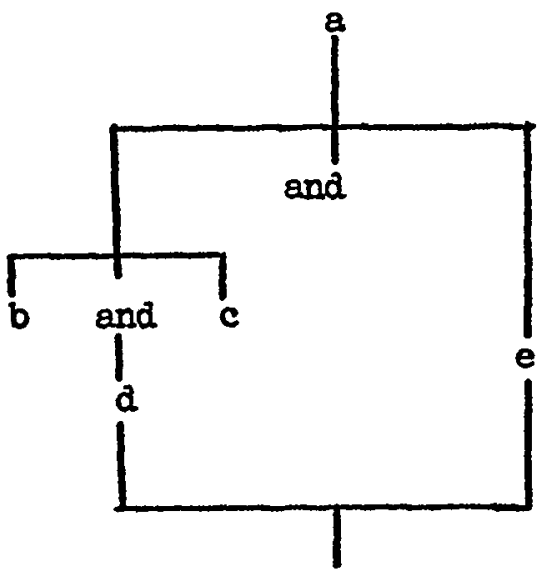

$"$ (D22.2) asserts "(a-(b-and-c)-d)-and-(a-c)." 
Sometimes, because the rest of the statement in which an "and" appears is so complex in its syntax, the task of analyzing that statement, to ascertain how it is appropriate to interpret it, is more difficult. An example of such a statement appears in section 673 $\mathrm{I}(\mathrm{e})$ of the Business and Professions Code of California. It reads:

(23) Nothing in this chapter shall prohibit the preparation $\frac{\text { of plans, drawings, }}{\mathrm{a}}$ $\frac{\text { specifications, }}{\mathrm{d}} \frac{\text { estimates }}{\mathrm{e}}$ or instruments $\frac{\text { of service }}{\mathrm{f}} \frac{\text { for }}{\mathrm{h}} \frac{\text { single }}{\mathrm{i}} \frac{\text { or multiple }}{\mathrm{j}}$ dwellings not more than two stories and basement in height; garages or $\mathrm{k} \overline{\mathrm{m}} \mathrm{n}$ other structures appurtenant to such dwellings; farm or ranch buildings; or $\mathrm{p} q \mathrm{q}$ s $\mathrm{t}$ any other buildings, except steel frame and concrete buildings, not over one $\overline{\mathrm{u}} \overline{\mathrm{w}} \mathrm{x}$ y story in height, where the span between bearing walls does not exceed $z$

twenty-five (25) feet.

In People v. Wright, ${ }^{53}$ the court, in rejecting defendant's contention that the phrase "steel frame and concrete buildings" refers to a single type of building constructed of steel frame filled with concrete, declared:

Such a construction is grammatically possible, but not necessary. In the context in which the phrase is used, it is the clear intent of the legislature, and a reasonable construction without violence to the words used, to construe the phrase as meaning steel frame buildings and concrete buildings. This is: the construction we place upon the phrase.

"When necessary to harmonize the provisions of a statute or give effect to all of its provisions, the word 'and' may be read as 'or,' and conversely. State v. Brandt, 4I Iowa 593." 3 Words and Phrases, "And," p. 595.

The first three sentences of this passage from the court's opinion suggest that the court interprets the phrase in question as represented by the diagram:

${ }^{82}{ }_{131}$ C.A.2d 853, 28I P.2d 384, 390 (1955). 
$\left(D_{23} \cdot \mathrm{x}\right)$

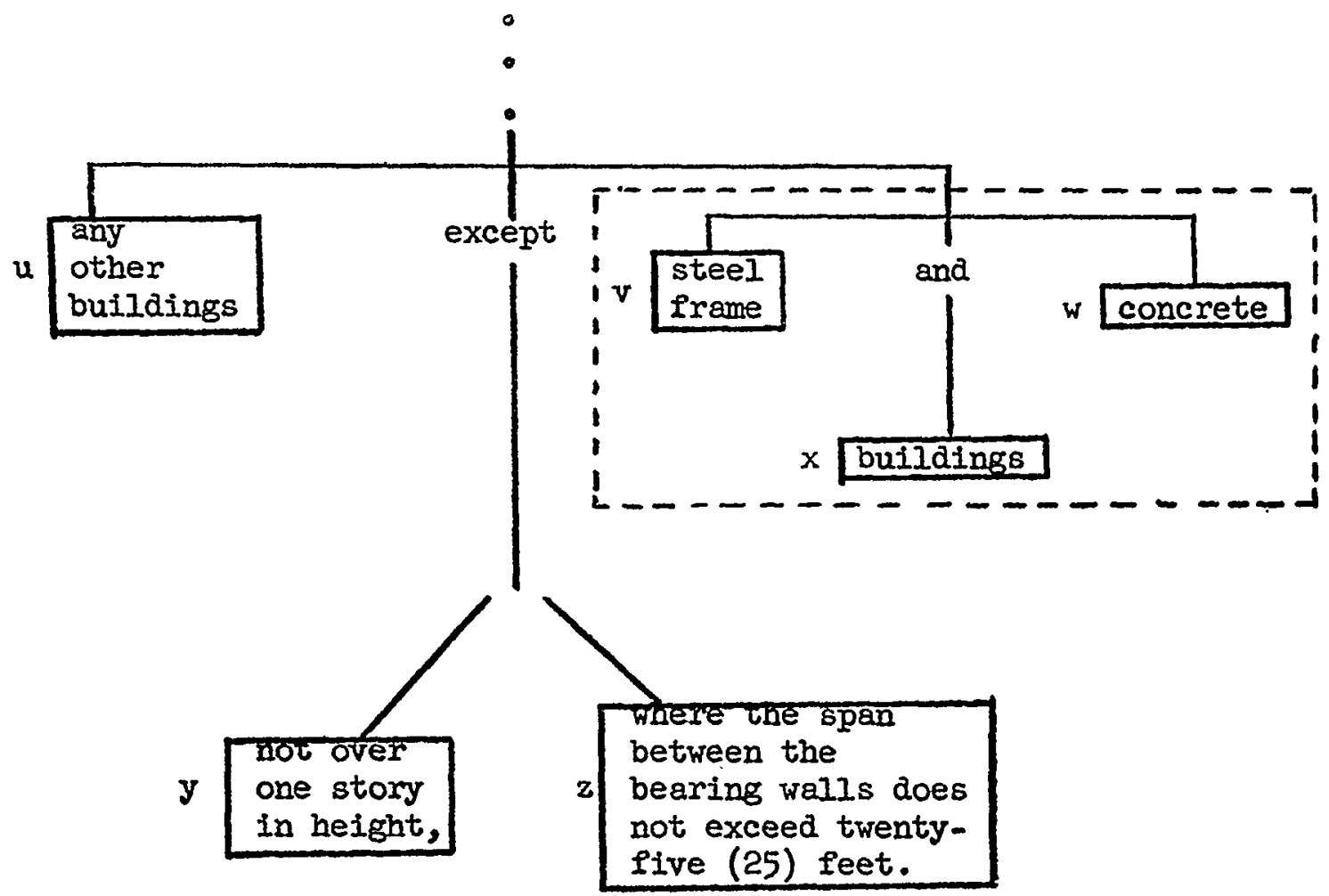

While the court's quotation from the Brandt case suggests that the appropriate interpretation is the one represented by the diagram:

(D23.2)

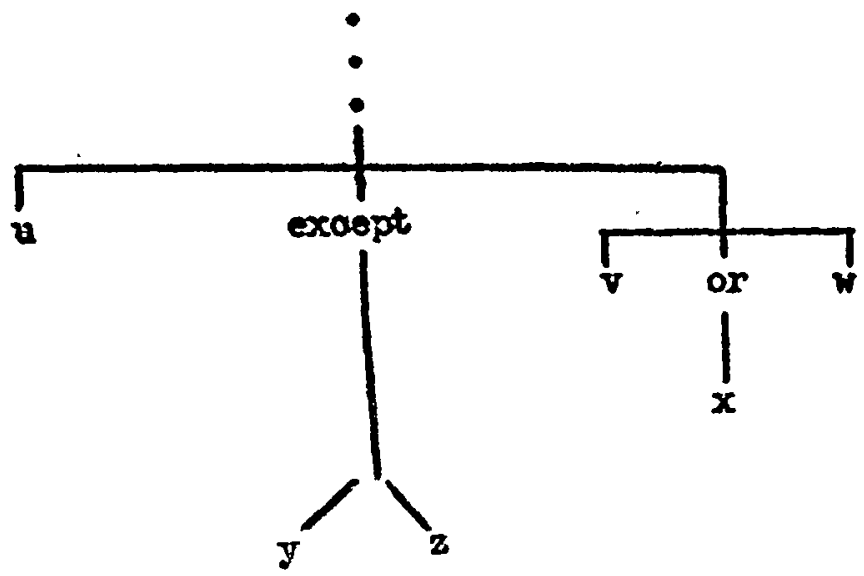


The interpretation represented by (D23.I) and (D23.2) both, of course, express the same idea as the interpretation represented by the diagram:

(D23.3)

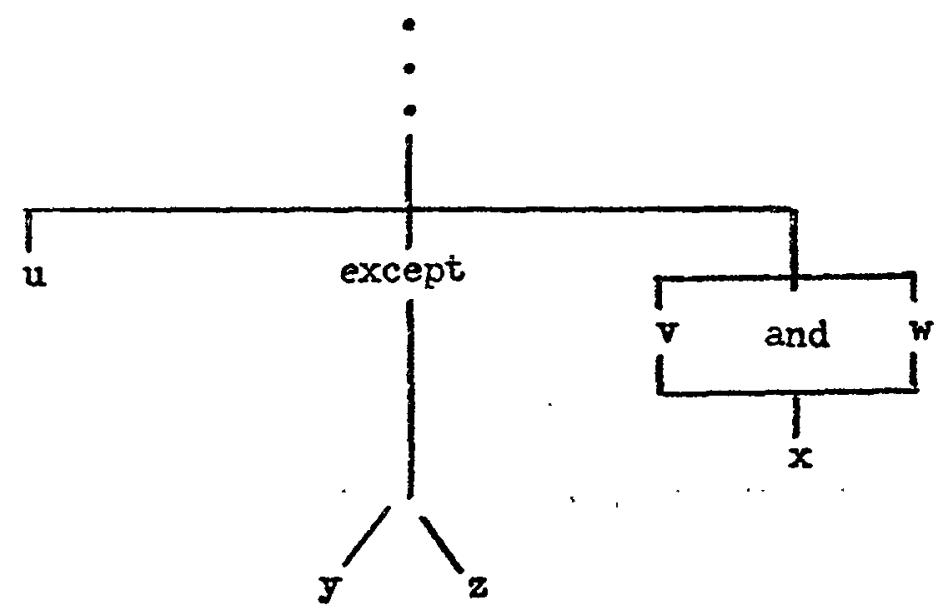

which, in turn, is an idea quite different from that expressed by the interpretation represented by the diagram:

(D23.4)

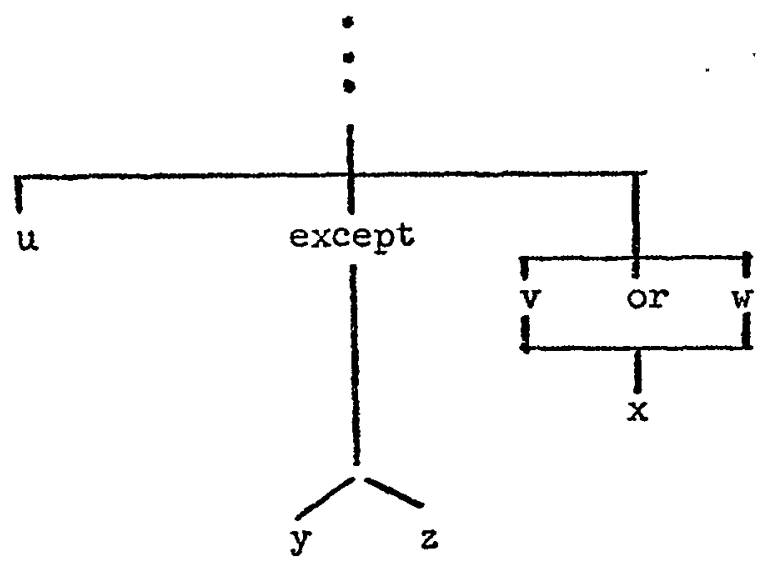

and also quite different from the idea expressed by the defendant's interpretation, which is represented by the diagram: $:^{54}$

It (D23-x) asserts " $\mathrm{u}$-(except-( $\mathrm{v}-\mathrm{x})$-and-(w-x))-y-z."

(D23.2) asserts " $\mathrm{u}$-(except-( $(\mathrm{v}-\mathrm{or}-\mathrm{w})-\mathrm{x})-\mathrm{y}-\mathrm{z}$."

(D23.3) asserts "(...u-(except- $\mathrm{v}-\mathrm{x})-\mathrm{y}-\mathrm{z})$-and-(...u-(except-w-x)-y-z)."

(D23.4) asserts "(...u-(except-v-x)-y-z)-or-(...u-(except-w-x)-y-z)."

(D23.5) asserts " $u-($ except-(v-and-w)-x)-y-z." 
(D23.5)

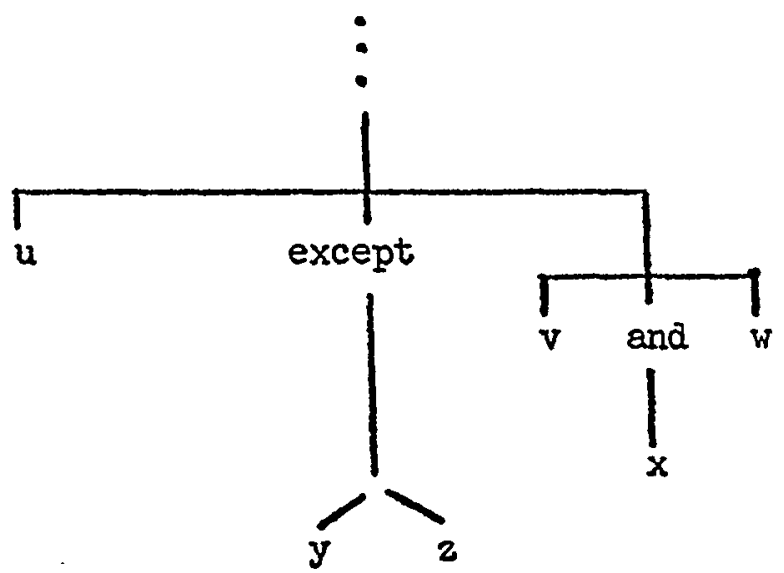

Why statement (23) seems complex becomes evident when (D23.3) is written out in full: 55
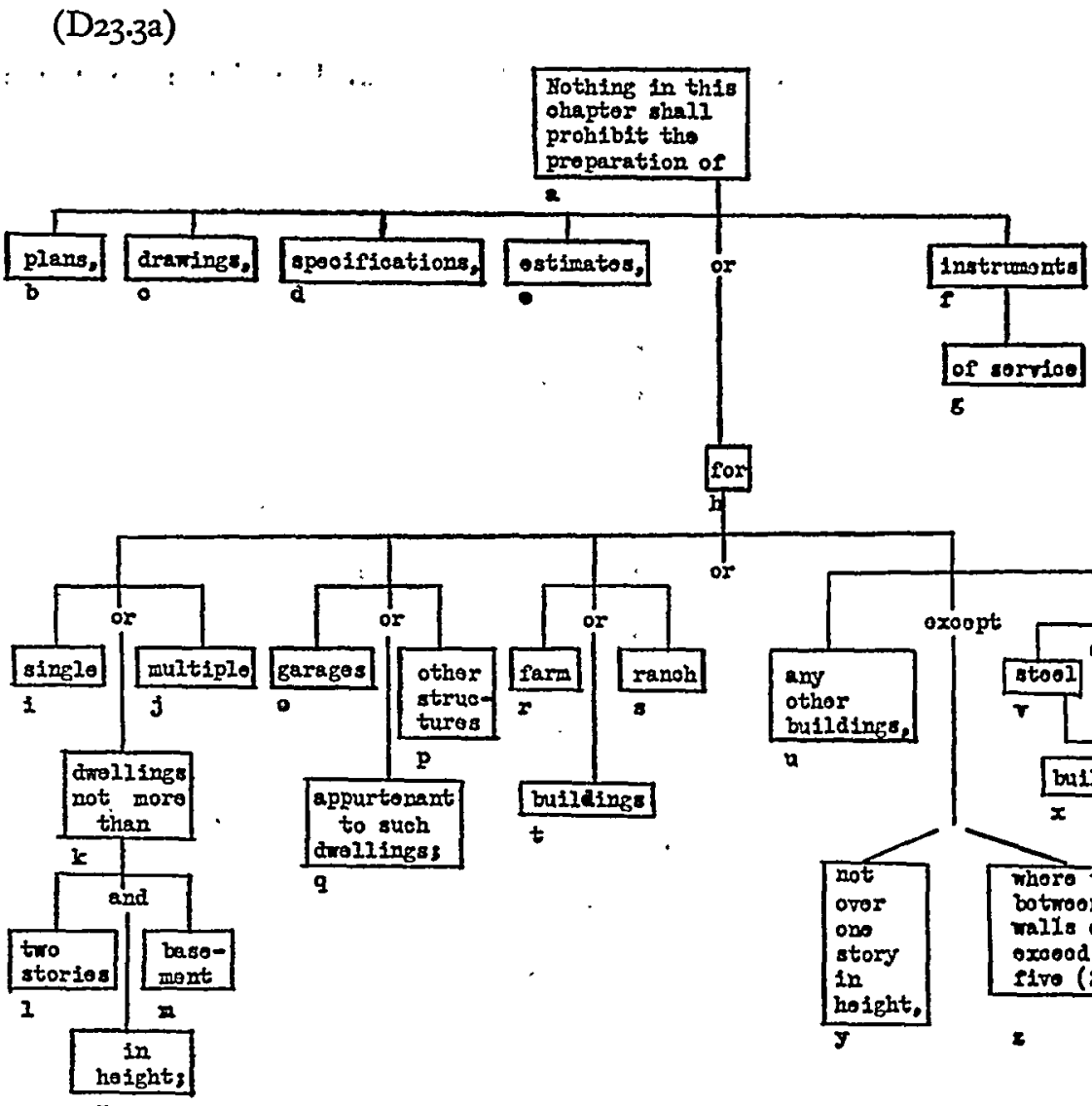
It should be noted that the connecting word "except" in (D23.3) may be ambiguous. The opinion in the Wright case makes it clear that the court interprets it as "*except," rather than as "*except*."

All of the examples considered here so far have focused on "and" as the connecting word. It should be emphasized that everything said with respect to "and" as a connecting word applies to other connecting words, as well. Consider the following sentences from Rule $\mathrm{I} 7$ (c) of the Federal Rules of Civil Procedure:

(24)

\section{Connecting Words (between sentences)}

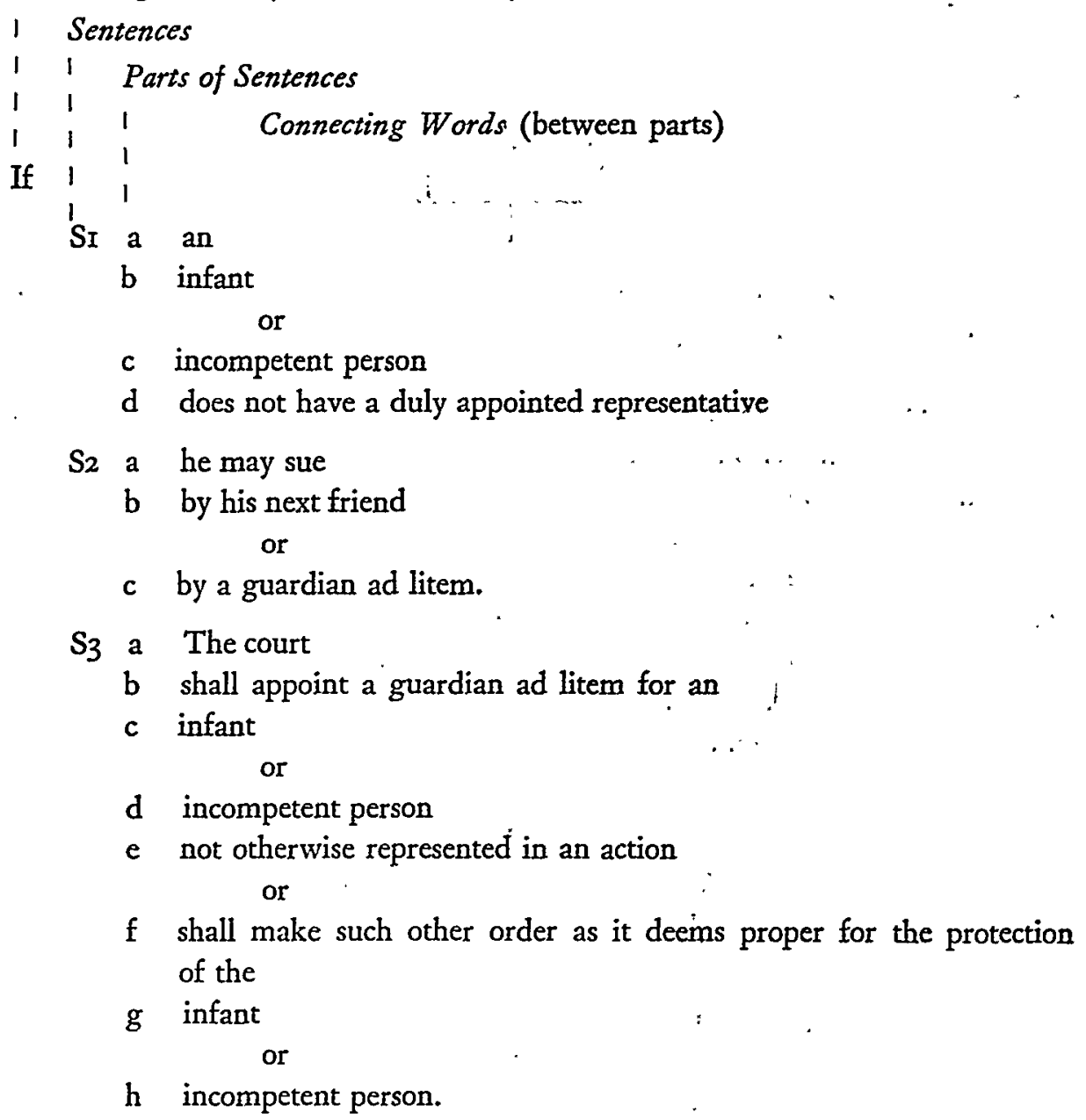

It seems quite clear that the appropriate interpretation of $S_{2}$ is that such an infant or incompetent person may sue by his, next friend and. he may sue by a guardian ad litem-that is, the interpretation represented by the diagram:

${ }^{\text {so }}$ See pp. $245-46$, supra. 
$\left(D_{24} \cdot S_{2 . I}\right)$

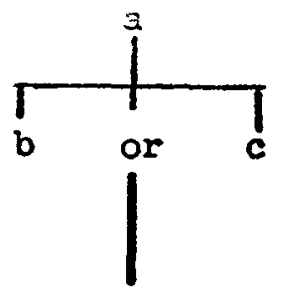

rather than the interpretation represented by the diagram:

(D24.S2.2)

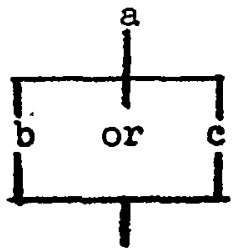

(D24-S2.1) asserts "a-(b-or-c)," which for this particular sentence is equivalent to "(a-b)-and-(a-c)," while (D24-S2.2) asserts "(a-b)-or-(a-c)"-something quite different.

However, the "or" in the very next sentence, $S_{3}$ of (24) is appropriately interpreted in a way that is similar to the second alternative for $\mathbf{S} 2$ rather than the first, according to the fourth circuit's decision in Wescott $v$. United States Fidelity \& Guaranty $\mathrm{Co}^{57}$ The court, affirming the trial court's action in issuing an order for the protection of the infant litigant and refusing to appoint a guardian ad litem, declared: "We cannot agree with the contention of appellants that the word 'or' in that last sentence [sentence $\left(S_{3}\right)$ ] reallys means 'and,' thus making the appointment of a guardian ad litem mandatory." In effect, the court rejected the interpretation represented by the diagram:

(D24-S3.I)

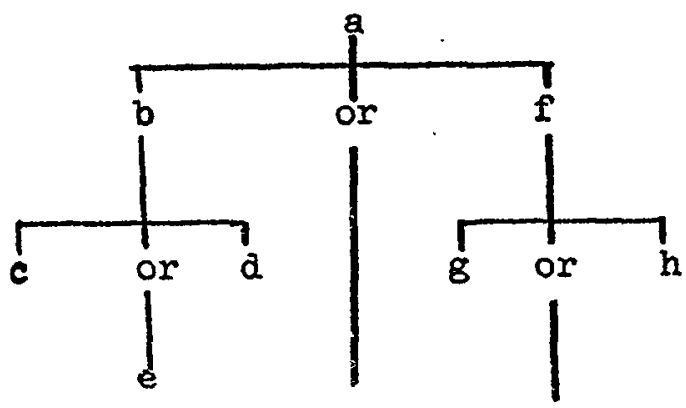

which, for this sentence, would be equivalent to the interpretation represented by the diagram:

${ }^{57} 15^{8}$ F.2d 20, 22 (4th Cir. 1946). 
$\left(D_{24} S_{3.2}\right)$

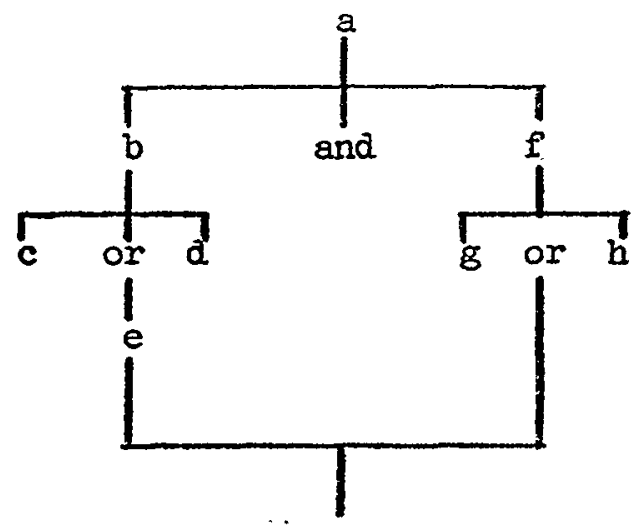

In deciding that the lower court was required only either to appoint a guardian ad litem or make some other appropriate order, but was not required to do both, the appellate court was accepting the interpretation represented by the diagram:

$\left(\mathrm{D}_{24}-\mathrm{S}_{3 \cdot 3}\right)$

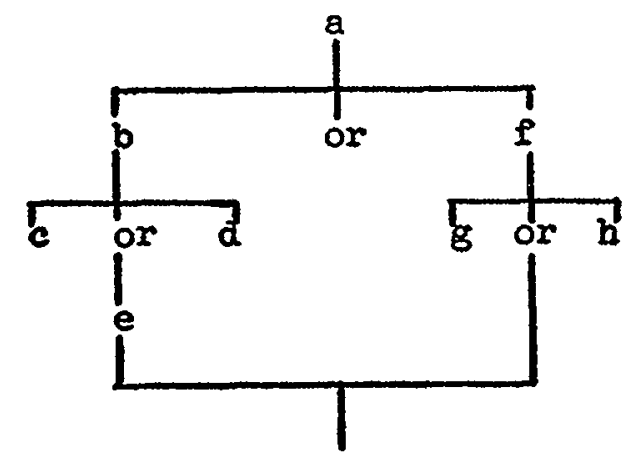

Even ( $\left.\mathrm{D}_{24} \cdot \mathrm{S}_{3.3}\right)$ is ambiguous, however, and its ambiguity can best be illustrated by a question not raised in the case, but one which the draftsman might have wished to resolve at the time the provision was written. It is whether this provision was intended to permit the lower courts to issue both kinds of orders or whether they were to be restricted to issuing just one or the other in a particular case. When the statement is diagrammed, the potential ambiguity is signalled by the absence of any asterisks adjacent to the middle "or." If the intent were to permit both kinds of orders in a particular case, the diagram would be: 
(D24-S3.3a)

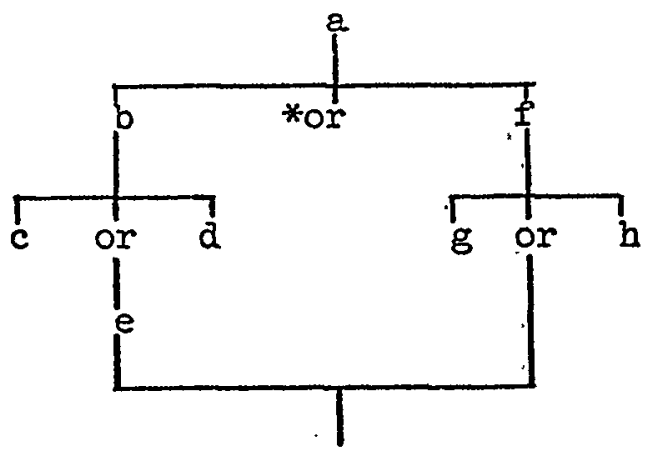

indicating an inclusive "or" (including the possibility of both). On the other hand, if the intention were to permit only one of the two kinds of orders in a particular case, the diagram would be:

(D24-S3.3b)

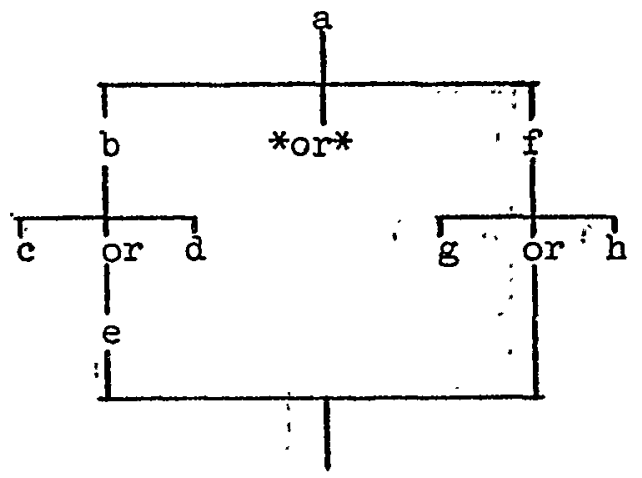

indicating an exclusive "or" (excluding the possibility of both).

The diagramming procedure that has been described in such ponderous detail here represents our present tentative method for representing alternative interpretations of syntactically ambiguous statements. The only virtue claimed for it is that it can be used to represent every alternative in every syntactically ambiguous statement in legal literature that we have yet encountered. However, because of the frequent number of times that we have had to modify prior approximations of this procedure in order to deal with counter-examples that could not be adequately represented by the procedure then being used, we expect that there exist further counter-examples for which the procedure will need to be further modified. One of our goals has been to accelerate the evolution through a series of successive approximations toward a method that will adequately handle just about all statements that appear in legal documents. While we do not have great confidence that 
the goal is nearly realized, the present techniques are significantly better than the efforts of the lawyer who proceeds by his verbal intuitions alone-judged by the quality of drafting that is displayed in legal literature. Further improvement will come when additional counter-examples arise and accommodations are made to deal with them.

\section{ConcLusion}

Nothing that has been said in the discussion here of the relationship between modern logic and the judicial process pretends to be definitive or final; our thoughts about this relationship are still quite tentative. Although logicians and lawyers share a common concern for ideas, reasoning, argument, and modes of expression, the full scope of the interrelations between logic and law is yet far from clear. As emphasized in the discussion, we have attempted to present only a sketch of one view of the relationship between logic and judicial decision making. By limiting our detailed presentation to a focus on Syntactic Rule Interpretation, we do not mean to suggest that this is the only, nor even the most important, lawyer-use of logical skills. Many important aspects of the overall Judicial Decision Process-a process that is uncomfortably elusive to describe-are treated only summarily, or even completely ignored, in the necessarily brief account here. Our primary goal has been to describe a procedure designed to assist lawyers in their drafting and interpretation of legal language. It may seem that felicity of expression has too frequently been sacrificed to demands for precision in the discussion of diagramming techniques. But hopefully, the stiff and repetitious prose style of that exposition will be compensated for by the usefulness of the method of analysis described.

Approached from the point of view suggested here, the use of modern logic in law is seen as a liberating tool, not a confining one; as a means of clarifying issues, not furnishing criteria for resolving them; as an aid for helping to communicate concisely and precisely when that is the goal that the communicator seeks. And thus viewed, its thrust in helping to improve communication is more toward preventing disputes than toward adjudicating them-more toward legislative determination of social policy than toward judicial action. Yet, unless professional recruitment and training patterns change radically in the near future, it is not likely that the bar will be overwhelmed by the number of lawyers in its midst who have a firm command of modern logical skills. However, for the oncoming generation in elementary and junior high schools today that is gaining some exposure to modern mathematics, the outlook is decidedly different. They will be better equipped. Still, it should not be overlooked that lawyers are notoriously apt as students when an occasion arises for a need to know. For those who may think they have no aptitude for mathematics (or mathematical logic), yet would struggle through a practical course in legal accounting, we have one question to ask: Is legal 'rithmetic 
more relevant than the readin'-n-writin' lawyer skills? For many the search for more effective modes of communication may have an additional dimension, one that Bernard Berenson has described so well: ${ }^{58}$ ". . . the joy of creative art comes when one is lured to hope that he has found the cypher, the symbol, the generic shape or scrawl, the hieroglyph, the convention, in short, that will do it . ..."

${ }^{\text {ts }}$ Bernard Berenson, Seetng and Knowing 7 (1953). 